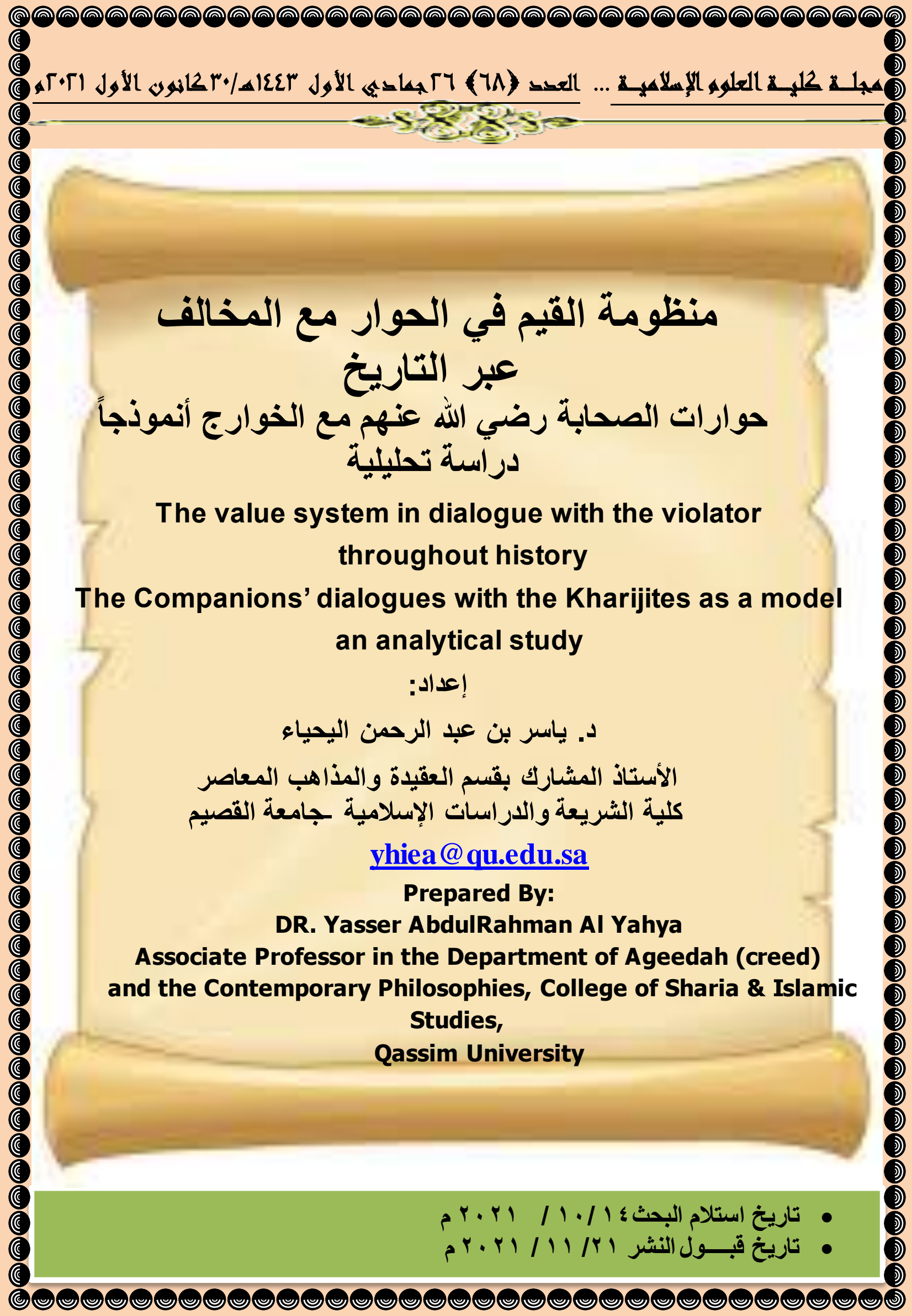




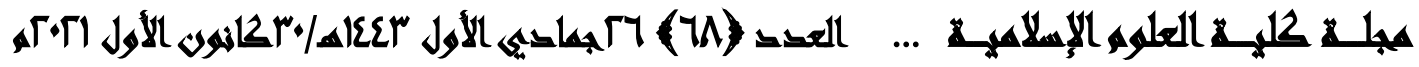

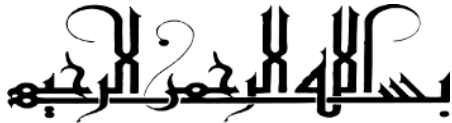

\section{ملفــ البحـــ}

يذهب البحث الى استجلاء منظومة القيم في الحوار مع المخالف من خلال التثتيش في تراثنا الثقافي، وقيمنا الدينية المتأصلة، وقد حاولت في هذا البحث أن أوقف هلف القارئ الكريم على شيءٍ من ذلك من خلال مواقف الصحابة رضي الله عنهم مع فرقة الخوارج المارقين الذين ظهروا في أواخر الخلافة الراشدة، وتتمثل هذه الموقف في محاوراتهم المتعددة والمتنوعة مع الخوارج سواء كان ذلك في بداية ظهورهم - كما هو الحال في محاورة علي وابن عباس رضي الله عنهم-، أو بعد تشكل فرقهم وقوة شوكتهم كما في محاورة ابن الزبير وجابر بن عبدالله رضي الله عنهم. وقد وقفت في هذه المحاورات على قيم مهمة في الحوار ، يحسن استلهامها والعمل

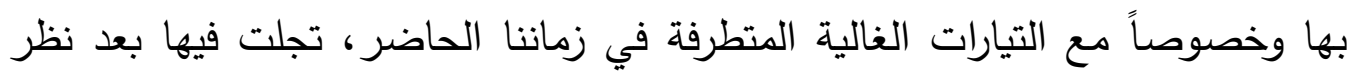
الصحابة وطول صبرهم، وقوة حجتهم، ورُقي أخلاقهم، وعدلهم مع المخالف قبل الموافق، وثقتهم بما عندهم من الحق والهدى والنور . 


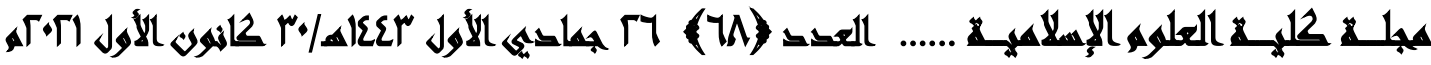

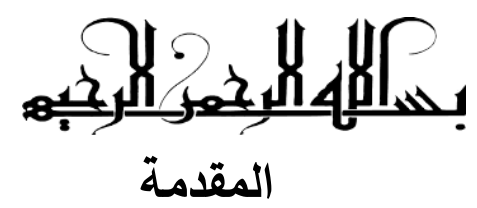

الحمد لله والصلاة والسلام على رسول الله وبعد: الحوار والمجادلة بالتي هي أحسن مع من تختلف معهم أياً كان هذا الخلاف أمر مشروع، جاء

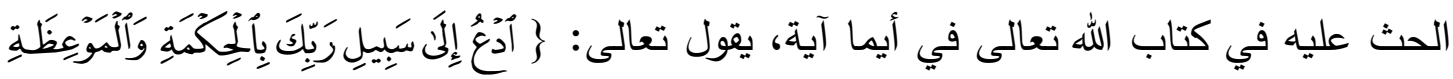

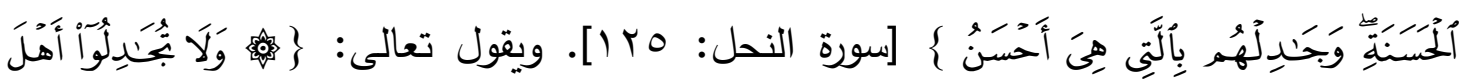

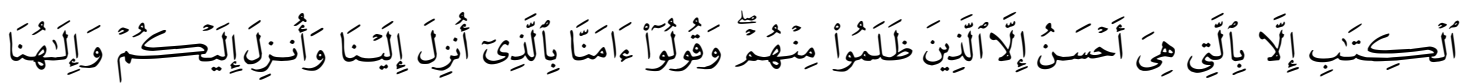

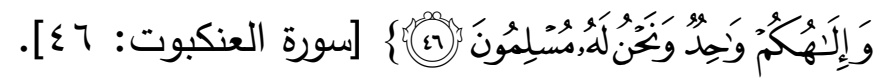
وقد سار الصحابة (رضي الله عنهم) الذين هم محل القدوة والأسوة لمن بعدهم- مع المخالفين في زمانهم هذه السيرة، حيث من المعلوم أن رؤوس الفرق -كفرقة الخوارج والقدرية والمرجئةظهرت قبل انقراض هذا العهد المبارك، فحفظت لنا كتب التاريخ والسير مواقف الصحابة، وطريقة تعاملهم، وكيف واجهوا تلك الفرق وحاوروهم ملتزمين المنهج النبوي القائم على العدل والقسط مع الموافق والمخالف. ومن هذه الفرق التي وقف لها الصحابة وجابهوا بدعتها علمياً وعملياً فرقة الخوارج المارقين، وتُعد بدعة الخوارج من أخطر البدع التي ظهرت في زمانهم، حيث أدت هذه البدعة إلى فتح باب الفتنة والفرقة بين المسلمين، وتكفيرهم والخروج على جماعتهم، وسفك دمائهم وانتهاك حرماتهم. وهذا يحتم علينا دراسة تلك المواقت والحوارات في التعامل مع المخالفين، لنستلهم منها الدروس

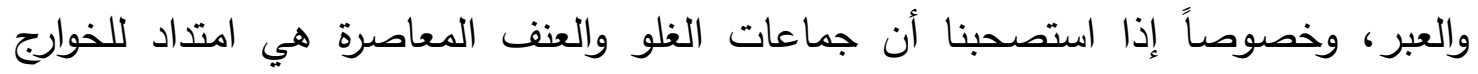
السابقين، حيث يستمدون عقائدهم منهم ويحاولون إعادة إنتاج أفكارهم، مما يضاعف المسؤولية العادية، ويعزز الأهمية لمعالجة مثل هذه الأفكار ومحاربتها. 


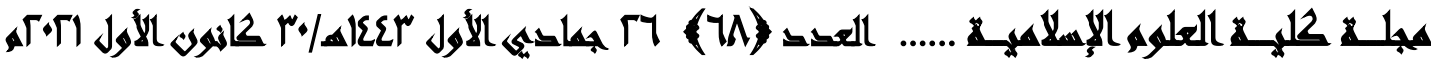

وهناك نماذج كثيرة لحوارات الصحابة مع الخوارج يحسن الوقوف عندها، واستجلاء أمرها لعل من أههها: حوار ابن عباس وعلي بن أبي طالب وعبدالله بن الزبير (رضي الله عنهم) مع

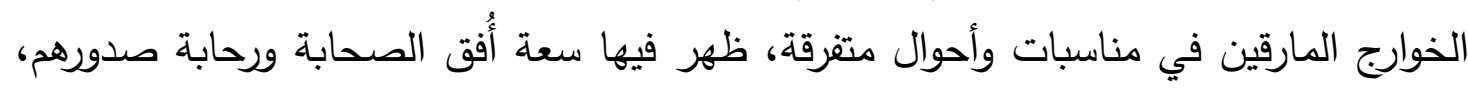
وطول صبرهم، حيث يحاورونهم ويجيبون على أسئلتهم واستفساراتهم المتعنتة، كل ذلك لعل هذا يكون سبباً في أوبتهم ورجوعهم. ونان. ومن هنا رغبت في إبراز هذه النماذج المهمة في الحوار ، حتى يتكئ عليهم من جاء بعدهم ممن يتصدى للفرق الغالية، وجعلت عنوانا للبحث هو: (منظومة القيم في الحوار مع المخالف عبر التاريخ: حوارات الصحابة (رضي الله عنهم) مع الخوارج أنموذجاً.

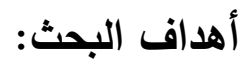
يهدف البحث إلى : - إنى ا - استجلاء الحوارات التي وقعت بين الصحابة وفرقة الخوارج لبيان الحق لهم وردهم عن ضالكهم. ז- استخراج منظومة القيم والأصول التي تضمنتها تلك الحوارات، ومن أبرزها قيمة العدل والإنصاف. ז- محاولة الإفادة من تلك الحوارات بما تضمنته من أفكار وأساليب في المحاورة والجدل، وتوظيفها في محاورة أصحاب فكر العنف والغلو. ع - بيان تثابه الأفكار والمنطلقات بين تيارات الغلو والعنف في القديم والحديث. أهمية الموضوع وأسباب اختياره:

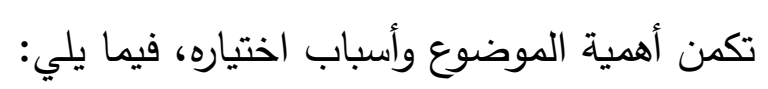
1- أن الحوار والمجادلة بالتي هي أحسن منهج رباني وهدي نبوي، يحسن إبرازه، وذكر تطبيقاته عبر تاريخ المسلمين. 


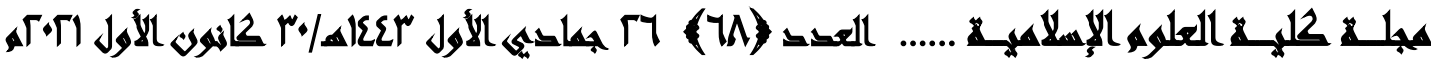

ץ- استلهام هدي الصحابة وسيرتهم في الحوار والمجادلة بالتي أحسن مع فرق الضلال في زمانهم، وخصوصاً أشدها غلواً وانحرافاً مثل الخوارج، لتصبح مرجعاً مهماً في ذلك، خصني الكوصاً أن الصحابة نجحوا في كبح جماح هذه الفرقة وتحييد تأثيرها وأثرها على ذلك المجتمع. r- ظهور جماعات الغلو والعنف في العصر الحاضر ، والتي تستلهج كثيراً من أفكار ومناهج ومصطلحات الخوارج المارقين، مما يستدعي الاستفادة من تجارب السابقين في علاج هذه الظاهرة.

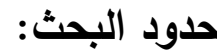
محاورات الصحابة للخوارج كثيرة لكن لعلي أقتصر على أبرزها وأكثرها عمقاً وأشدها أثراً، وهي حوارات: ابن عباس، وعلي ابن أبي طالب، وعبدالله ابن الزبير •

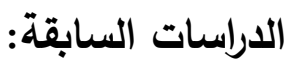
كثيرٌ هي الدراسات حول فكر الخوارج وعقائدهم وتاريخهم، لكن من خلال البحث والتقصي لم أقف على دراسة خاصة تبرز منظومة القيم الحوارية في حوار الصحابة ومجادلتهم للخوارج، ومحاولة استخراج الدروس والعبر من تلك الحوارات الثرية والنافعة.

منهج البحث:

منهجي يقوم على المنهج الاستقرائي والتحليلي، وذلك بتتبع حوارات الصحابة مع الخوارج من مظانها، والحكم عليها من جهة الرواية، ثم التعليق عليها، ومحاولة استخراج الدروس والعبر من تلك الحوارات ما أمكن.

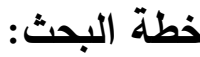

وسأسير في هذا البحث على النحو التالي: - مقدمة: أبين فيها أهمية الموضوع وأسباب اختياره. أولاً: بيان المقصود بالحوار وأهم أهدافه وفيه 


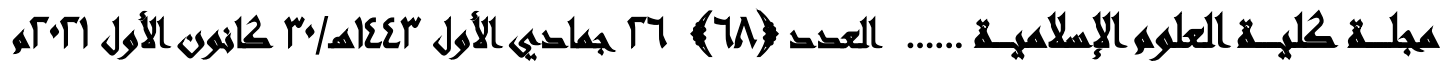

ثانياً: التعريف بالخوارج.

- - المبحث الأول: حوار علي وابن عباس (رضي الله عنهم) مع الخوارج

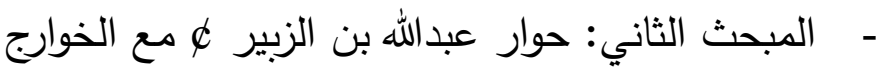

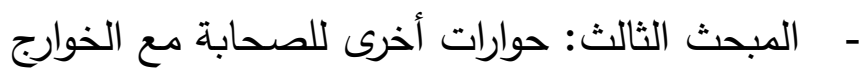
خاتمة: أخلص فيها لأهم النتائج.

هذا وأسأل الله العلي القدير أن يوفقني وإياكم لما فيه خيري الدنيا والآخرة.

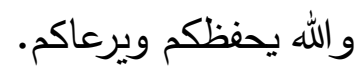




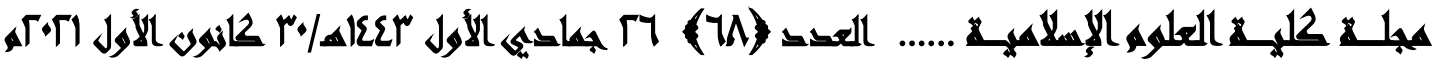

\section{التمهيد}

$$
\text { - أولاً: المقصود بالحوار : }
$$

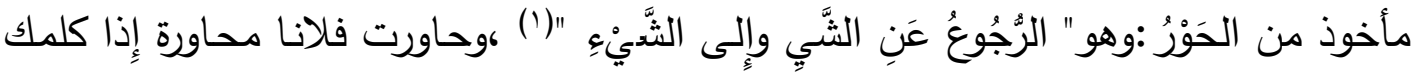

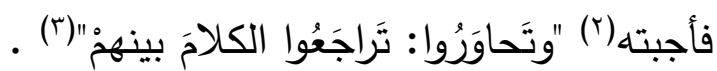

$$
\text { وفي الاصطلاح: }
$$

هو: الطريقة التي يستعملها المحاور مع الطرف الآخر في موضوع محدد بهدف الوصول إلى الحق من خلال إقناعه وتصحيح خطئه ما أمكن (؛). - - أهداف الحوار ومقاصده: -

1 - إقامة الحجة: الغاية من الحوار إقامة الحجة ودفع الثبهة والفاسد من القول والرأي. والسير بطرق الاستدلال الصحيح للوصول إلى الحق.

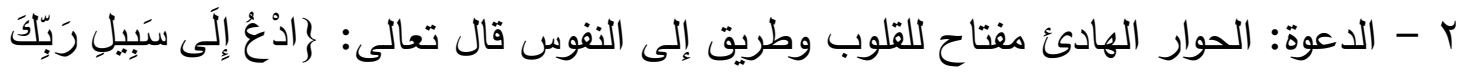

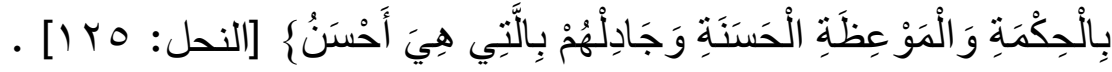

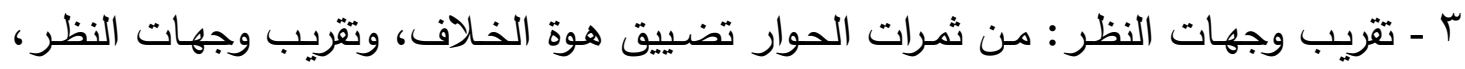
وإيجاد حل وسط يرضي الأطراف في زمن كثر فيه التباغض والتناحر . ع - كشف الثبهات والرد على الأباطيل، لإظهار الحق وإزهـاق الباطل، كمـا قـال تعـالى:

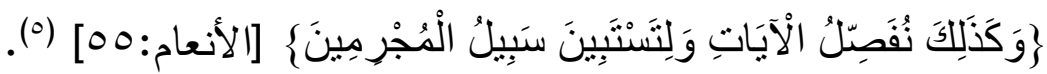
وأما المقصود بـ(قيم الحوار): " فهي مجموعة من المثل والأخلاق التي يتحلى بها المحاور استتاداً لتراثه وأصالته-سلباً أو ايجاباً - وذلك في أثناء المواقف الحوارية"(آ). وأهم قيم الحوار مع المخالف :الصدق، وإردة الحق في الحوار، والموضوعية (الإنصاف)، وقوة

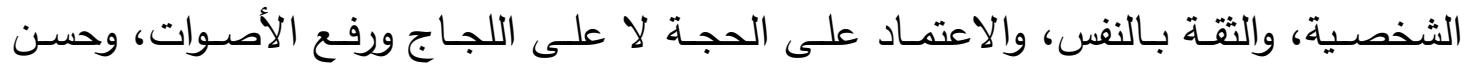




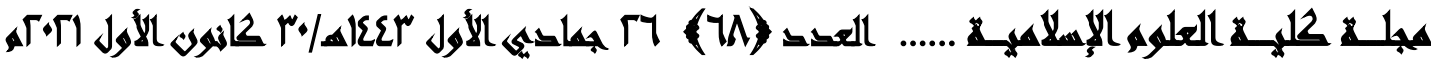

الاستماع وعدم الاستئثار بالحديث، والأمانة بالعرض، والصبر ، واحترام الآخر، واختيار المكان

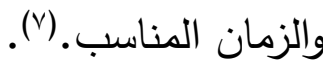
• • - الخوارج في اللغة: جمع خارج والنسبة إليه: خارجي، وقد أطلقت هذه الكلمة في كتب اللغة على طائفة من أهل الآراء والأهواء؛ لخروجها على الدين، أو على أمير المؤمنين عليها.

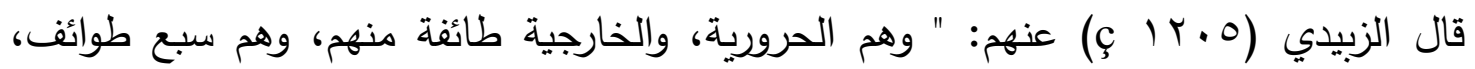
سمُّوا بهم لخروجهم على الناس، أو عن الدين، أو عن الحق، أو عن علي له بعد صفين"(^).

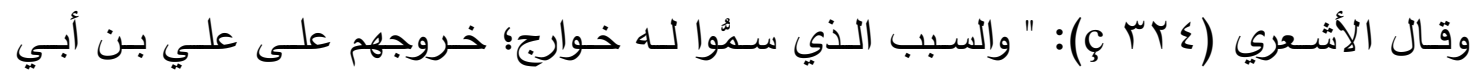

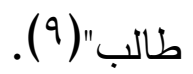

\section{- نشأة الخوارج ووقت ظهورهم:}

الذي يذهب إليه كثير من مؤرخي الفرق أن اللحظة التاريخية لظهور الخوارج كفرقة ذات اتجاه سياسي وفكر خاص، هي حين خرجوا على أمير المؤمنين علي ل لبعد أن رضي بالتحكيم في هوني موقعة صفين، والتحموا معه في معركة النهروان.

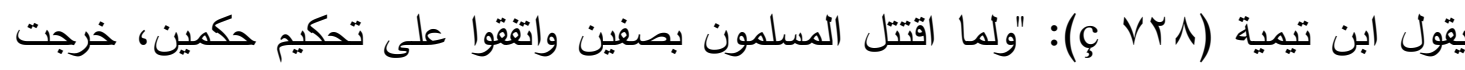
الخوارج على أمير المؤمنين علي بن أبي طالب، وفارقوه وفارقوا جماعة المسلمين إلى مكان يقال له حروراء، فكفَّ عنهم أمير المؤمنين، وقال: لكم علينا أن لا نمنعكم حقكم من الفيء، ولا ولا

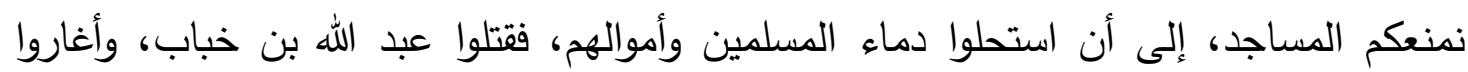
على سرح المسلمين؛ فعلم علي أنهم الطائفة التي ذكرها رسول الله ‘... فخطب الناس وأخبرهم بما سمع من رسول الله ،، وقال: هم هؤلاء القوم قد سفكوا الدم الحرام، وأغاروا على سرح

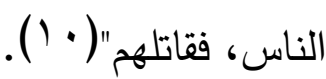




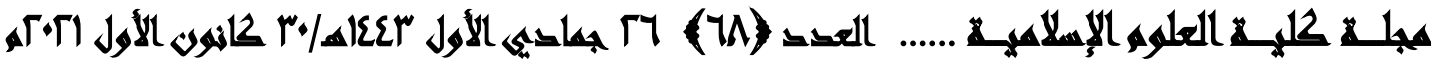

المبحث الأول: حوار علي وابن عباس (رضي الله عنهم) مع الخوارج:

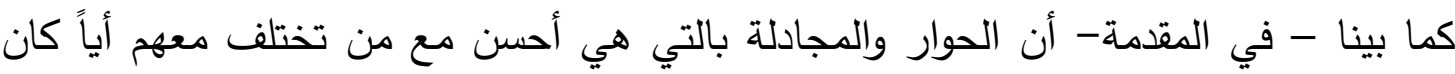

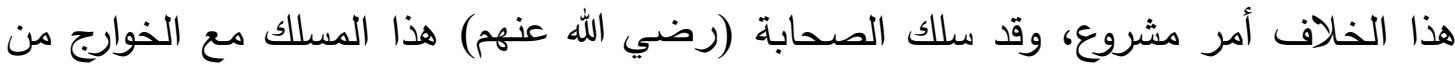

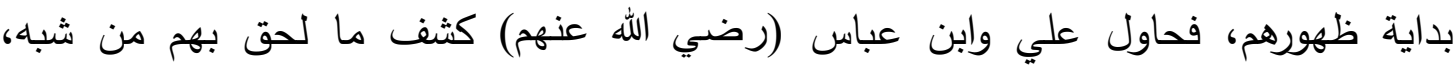

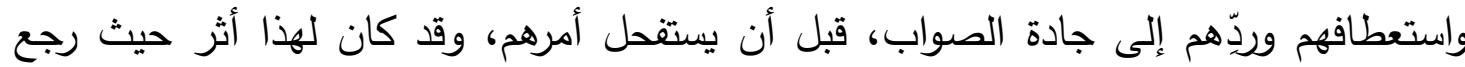

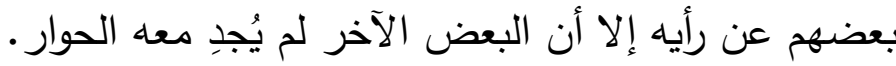

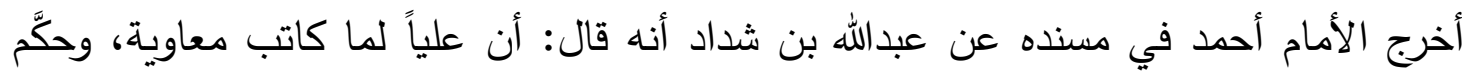
الحكمان، خرج عليه ثمانية آلاف من قراء الناس، فنزلوا بأرض يقال لها: حروراء، من جانب التهائ الكوفة، وإنهم عتبوا عليه فقالوا: انسلخت من قميص ألبككه الله تعالى، واسم سماك الله تعالى لهاه

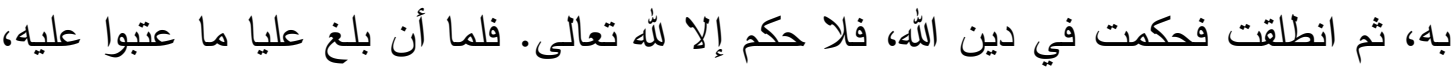

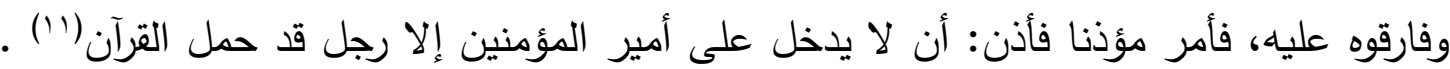

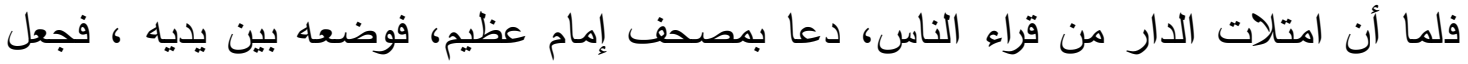
يصكه بيده ويقول: أيها المصحف، حدث الناس، فناداه الناس فقالوا: يا أمير المؤمنين، ما تسأل عنه إنما هو مداد في ورق، ونحن نتكلم بما روينا منه، فماذا تريد؟ قال: أصحابكم هؤلاء الذين

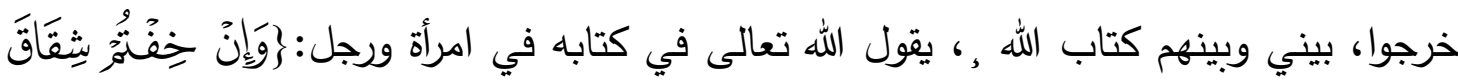

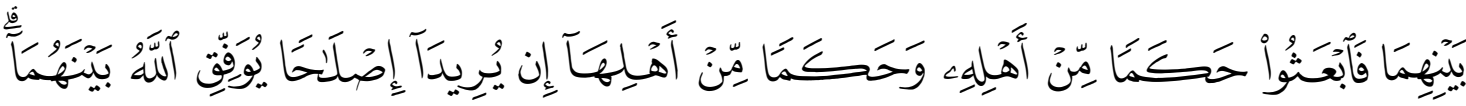

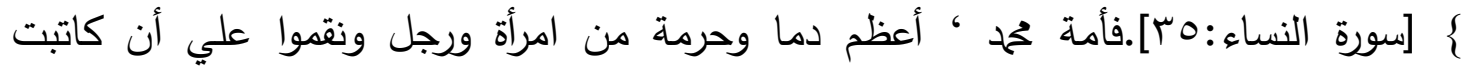

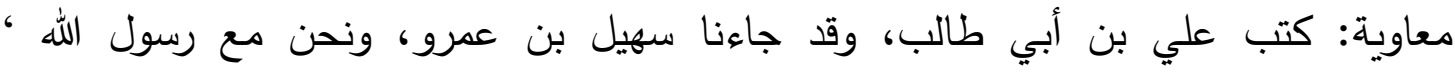
بالحييبة، حين صالح قومه قريشا، فكتب رسول الله ': ابسم الله الرحمن الرحيمه ـ فقال: سكيل لا تكتب: بسم الله الرحمن الرحيم. فقال: 》كيف نكتب؟؟ فقال: اكتب باسمك اللهم، فقال رسول الله “: " فاكتب: محمد رسول الله " فقال: لو أعلم أنك رسول الله لم أخالفك. فكتب: هذا ما صالح كحم بن عبد الله قريشا. يقول: الله تعالى في كتابه: لقد كان لكم في رسول الله أسوة حسنة لمن 


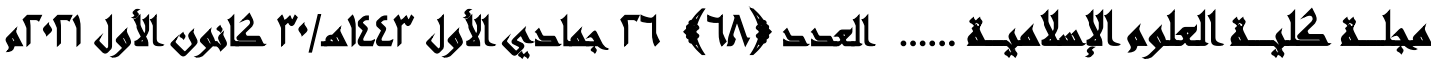

كان يرجو الله واليوم الآخر " فبعث إليهم علي عبد الله بن عباس، فخرجت معه، حتى إذا

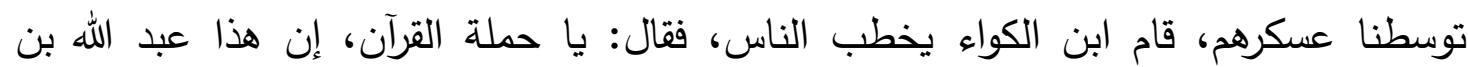
عباس، فمن لم يكن يعرفه فأنا أعرفه من كتاب الله ما يعرفه به، هذا ممن نزل فيه وفي قومه: قوم خصمون فردوه إلى صاحبه، ولا تواضعوه كتاب الله. فقام خطباؤهم فقالوا: والله لنواضعنه كتاب الله، فإن جاء بحق نعرفه لنتبعنه، وإن جاء بباطل لنبكتنه بباطله. فواضعوا عبد الله الكتاب ثلاثة أيام، فرجع منهم أربعة آلاف كلهم تائب، فيهم ابن الكواء، حتى أدخلهم على علي لهاء

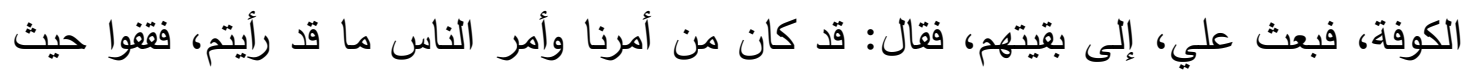
شئتم، حتى تجتمع أمة محمد ، بينتا وبينكم أن لا تسفكوا دما حراما، أو تقطعوا سبيلا، أو تظلموا ذمة، فإنكم إن فعلتم فقد نبذنا إليكم الحرب على سواء، إن الله لا يحب الخائنين"(rا'). وقد جاء تفصيل حوار ابن عباس ه للخوارج في موضع آخر ولأهميته يحسن إيراده: يقول ابن عباس ه: 》الما خرجت الحرورية اجتمعوا في دار، وهم ستة آلاف، أتيت علياً، فقلت: يا أمير المؤمنين، أبرد بالظهر لعلي آتي هؤلاء القوم فأكلمهم. قال: إني أخاف عليك. قلت:

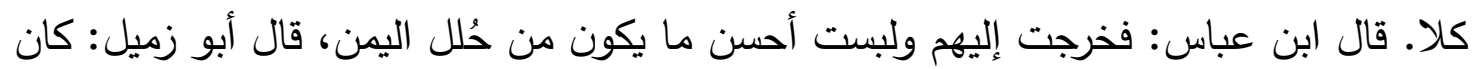

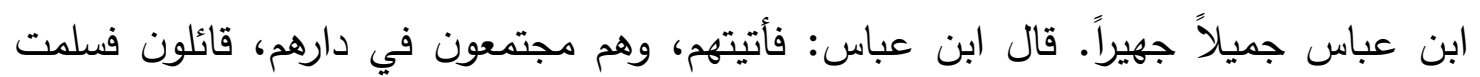

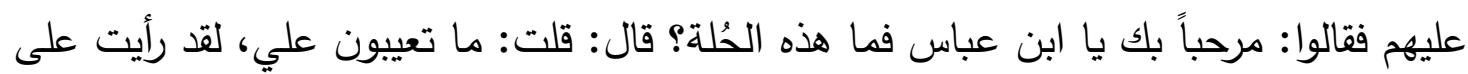

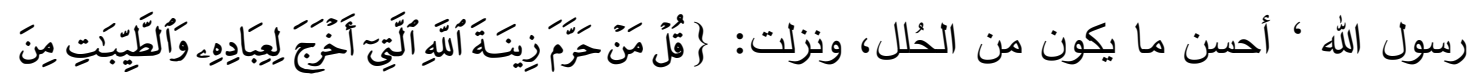

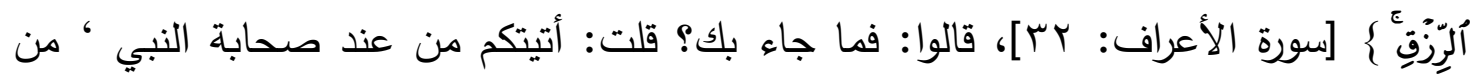
المهاجرين والأنصار، لأبلغكم ما يقولون المخبرون بما يقولون، فعليهم نزل القرآن، وهم أعلم بالوحي منكم، وفيهم أنزل: وليس فيكم منهم أحد. فقال بعضهم: لا تخاصموا قريشاً، فإن الله

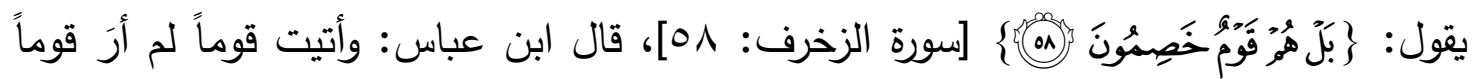

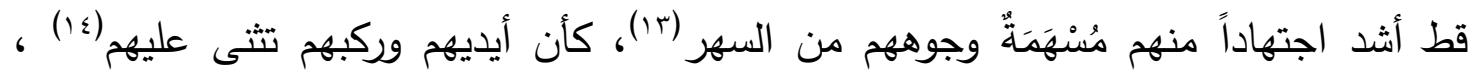

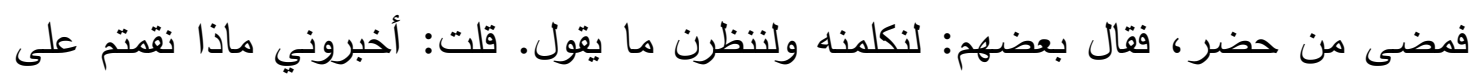




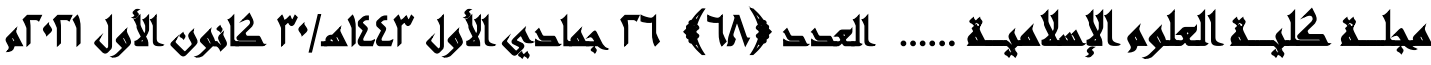

ابن عم رسول الله ‘، وصهره والمهاجرين والأنصار؟ قالوا: ثلاثاً. قلت: ما هن؟ قالوا: أما

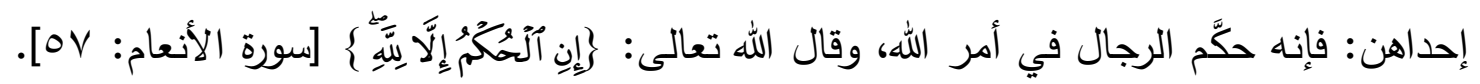
وما للرجال وما للحكم؟ فقلت: هذه واحدة. قالوا: وأما الأخرى؟ فإنه قاتل، ولم يسب ولم يغنم، فلئن كان الذي قاتل كفاراً لقد حل سبيهح وغنيمتهم، ولئن كانوا مؤمنين ما حلَّ قتالهم. قلت: هذها وله

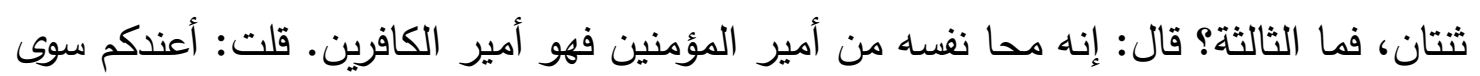

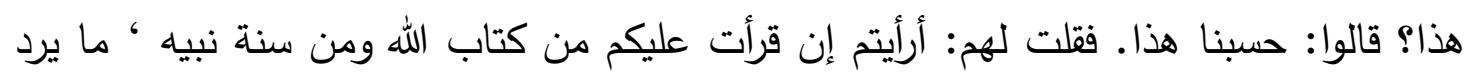
به قولكم أترضون؟ قالوا: نعم. فقلت: أما قولكم: حكَّم الرجال في أمر الله، فأنا أقرأ عليكم ما قد

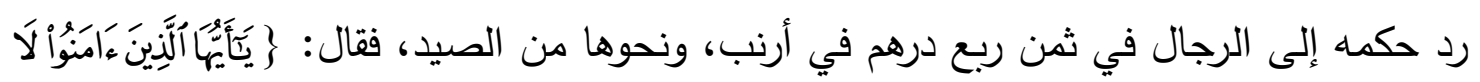

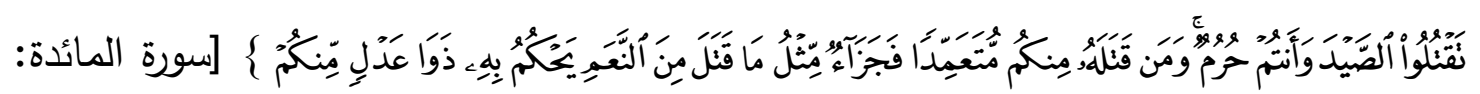
90]، فنشدتكم الله أحكم الرجال في أرنب ونحوها من الصيد أفضل، أم حكمه في في دمائهم وصلاح ذات بينهج؟ وأن تعلموا أن الله لو شاء لحكم ولم يصيّر ذلك إلى الرجال، وفي المرأة

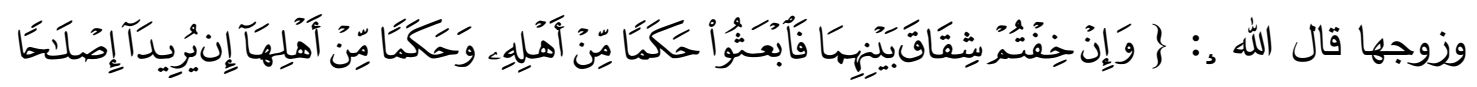
يُوَفِقِّ أَلَّهُ ؛ [سورة النساء: هب]، فجعل الله حكم الرجال سنة مأمونة، أخرجت عن هذه؟ قالوا: نعم، قال: وأما قولكم: قاتل ولم يسب ولم يغنم، أتسبون أمكم عائشة ثم يستحلون منها ما ما مأه يستحل من غيرها؟ فلئن فعلتم لقد كفرتم وهي أمكم، ولئن قلتم: ليست أمنا لقد كفرتم فإن الله

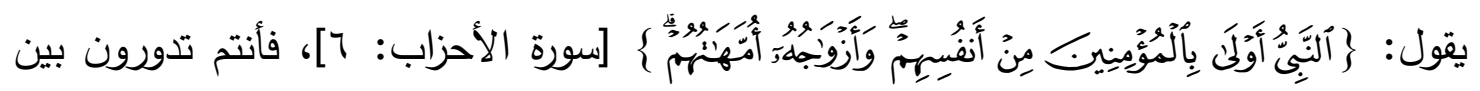

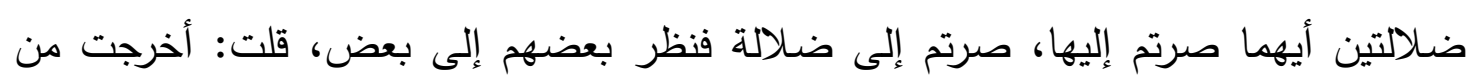

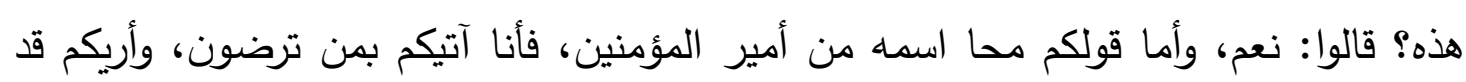
سمعتم أن النبي ، يوم الحديبية كاتب سهيل بن عمرو وأبا سفيان بن حرب فقال رسول الله ،

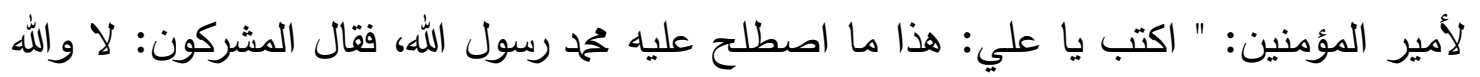
ما نعلم أنك رسول الله، لو نعلم أنك رسول الله ما قاتلناك، فقال رسول الله ‘: اللهم إنك تعلم أني 


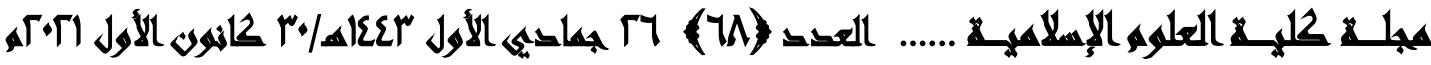

رسول الله، اكتب يا علي: هذا ما اصطلح عليه محمد بن عبد الله" فوالله لرسول الله خير من علي، وما أخرجه من النبوة حين محا نفسه، قال عبد الله بن عباس: فرجع من القوم ألفان، وقتل سائرهم على ضلالةهة (10).

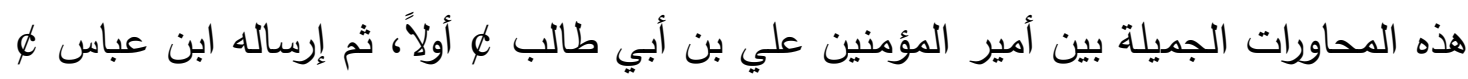

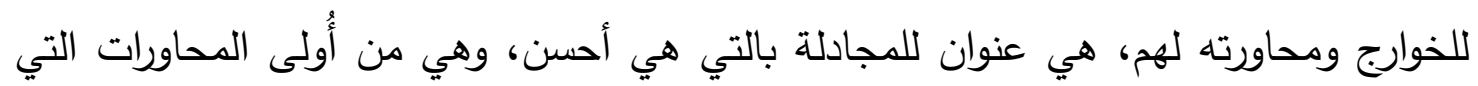
وقعت بين الصحابة والخوارج لثيهح عن بدعته وخروجهم على جماعة المسلمين. وقد اشتملت على مجموعة من القيم الحوارية التي يحسن الوقوف عندها، والتأمل فيها:

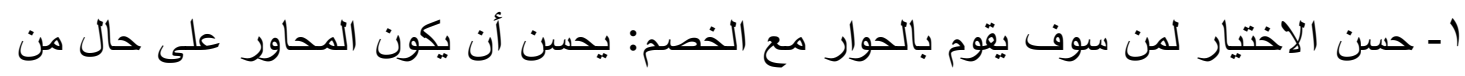

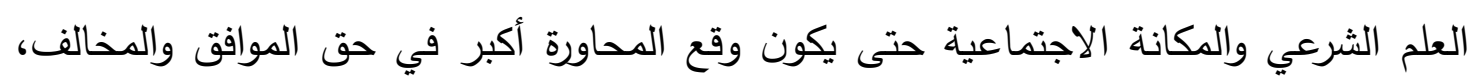
وهذا يعزز جانب قيمتين مهمتين في الحوار وهما(الثقة بالنفس وقوة الثخصية)وهكذا كان علي وابن عباس (رضي الله عنهم). فعلي" لا يخفى علمه وحكمته وبُعد نظره على أحد، مع ما كان عليه من قوة وصلابة في (ردي الرأي..

وكذلك ابن عباس حبر الأمة وترجمان القرآن، ولأن الخوارج كانوا يُعرفون بالقرآن، ويعتمدون في

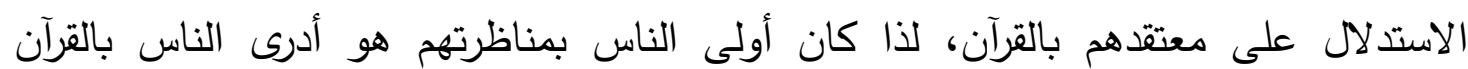
وبتأويله.

ومما يؤكد وجود هاتين القيمتين الحوارتين في شخص علي وابن عباس (رضي الله عنهم)، أنهم هم من بادر وطلب المحاورة، لعلمه وإيمانهم الأكيد أن الحق معهم، ولهذا لم يهابوا محاورتهم أو يتاخروا عنها.

r- تحديد الأرضية المشتركة ونقاط الاتفاق بين المتحاورين: حيث جعلوا بينهم وبين الخوارج أرضية مشتركة يرجعون إليها عند الاختلاف وهي الكتاب والسنة، وهذا ظاهر في محاورة علي

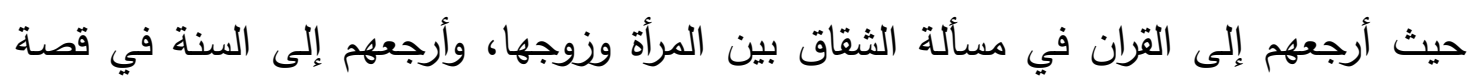




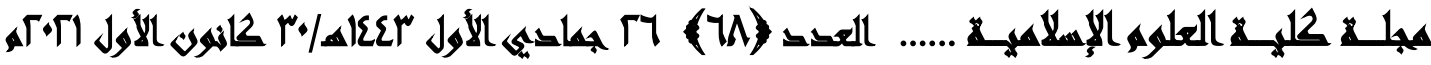

صلح الحديبية. وهو أشد ظهوراً في محاورة ابن عباس لهم حيث طلب إقرارهم على هذا فأقروه عليه: " فقلت لهم: أرأيتم إن قرأت عليكم من كتاب الله ومن سنة نبيه ، ما يرد به قولكم أترضون؟ قالوا: نعم".

وهذا يعزز قيمة حوارية مهمة وهي (الاعتماد على الحجة)، لا على اللجاج ورفع الصوت أو كثرة العدد، وقد حاول بعض الخوارج صرف أصحابهم عن محاورة ابن عباس غ بأمور خارجة عن محل الحوار والنقاش كما فعل ابن الكواء- كما مر -، لعلمه بضعف حجتهم وقلة حيلتهم لكنه لم يفلح.

r- استيعاب شبه المحاورين ورأيهم قبل محاورتهم: وهذا مهم جداً من أجل قطع حججهم فلا

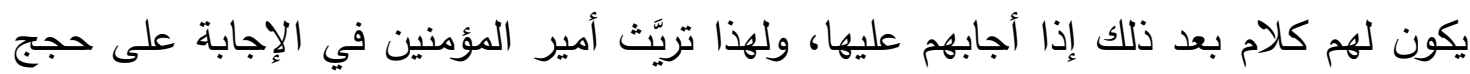
الخوارج مع كثرة اعتراضهم عليه، حتى عرف أنهم إنما ينقمون عليه ما ذكروه ثم دعاهم

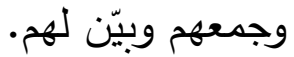
وكذلك ابن عباس ه طلب منهم في بداية المناظرة فقال: "قلت: أخبروني ماذا نقتم على ابن عم رسول الله “، وصهره والمهاجرين والأنصار ؟ قالوا: ثلاثاً. قلت: ما هن؟ ". وهذا الصنيع من علي وابن عباس (رضي الله عنهم) يؤكد على قيم حوارية مهمة ك(احترام رأي المخالف، وحسن الإنصات، والموضوعية) مع أن طرفي الحوار لا نسبة بينهما في التقابل والمقارنة إطلاقاً، فأين هؤلاء من علي وابن عباس (رضي الله عنهم) من جهة الفضل والقدر

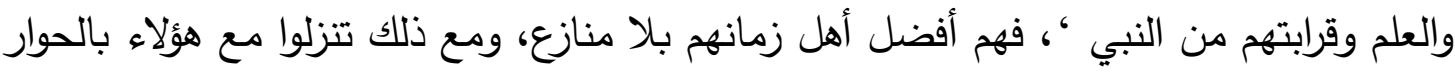
وسماع ما عندهم، والتلطف معهم، وعدم التقليل من مقامهم، وهذه قيم الحوار مع المخالف العزيزة التي قلّ من تقوى نفسه على امتثالها. ــ الإجابة على جميع حجج المناظر -ما أمكن-: وهذا ما حصل من علي وابن عباس حيث أجابوا عليها كلها، ضمن ما اتفقوا عليه من الرجوع فيها إلى الكتاب والسنة. وهذا يؤكد قيم مهمة من قيم الحوار وهي (والصدق وإرادة الحق، وعدم الحيدة عن محل النقاش)، فعلي وابن 


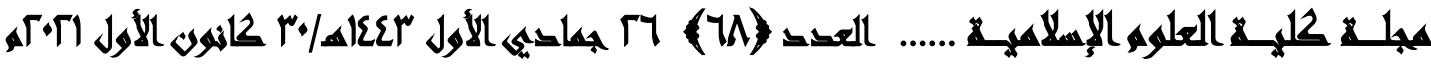

عباس (رضي الله عنهم) لم يكتموا أمراً، ولم يحيدوا عما سألهم عنه الخوارج ،وكل هذا دليل على إرادة الحق وطلبه.

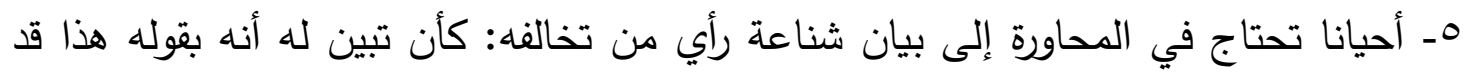

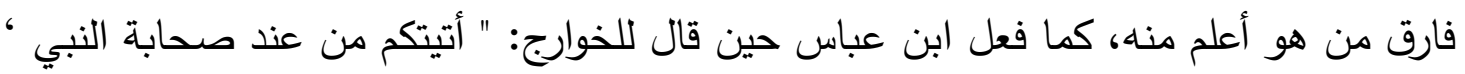

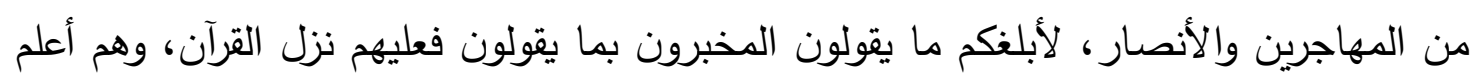

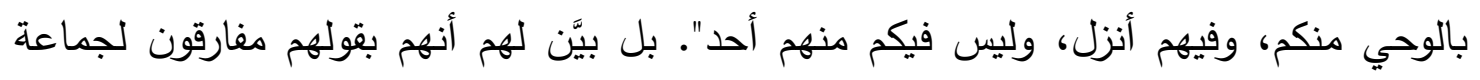

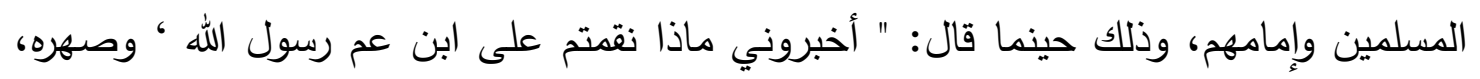

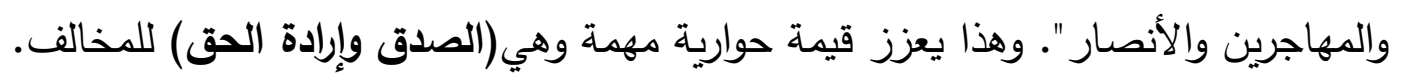

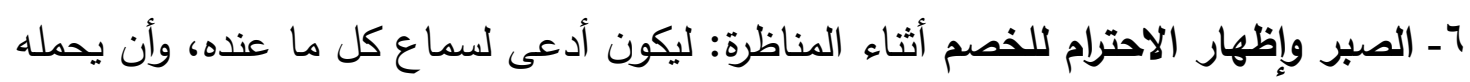
على احترام رأيه، وهذا ما ظهر من فعل أمير المؤمنين وابن عباس للخوارج.

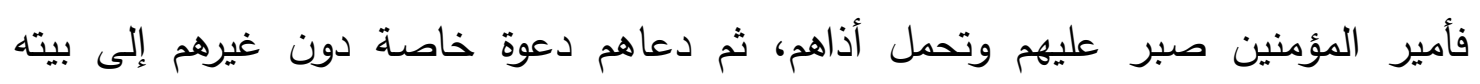

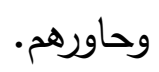

وكذلك ابن عباس ذهب إليهم مع أن حقه أن يأتوه وتحمّل كلامهم فيه، ثم حاورهم.

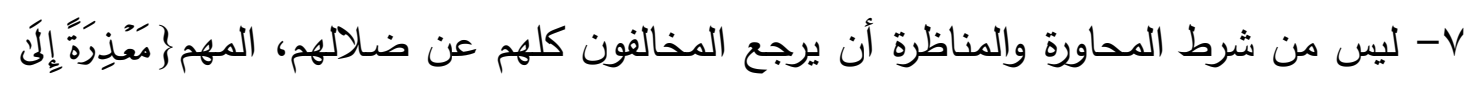

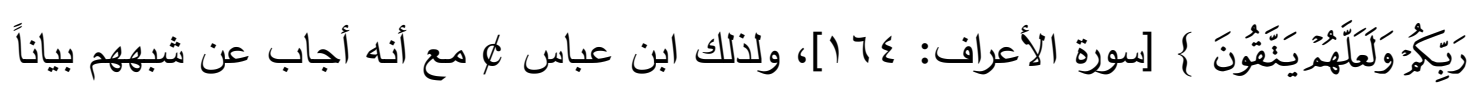

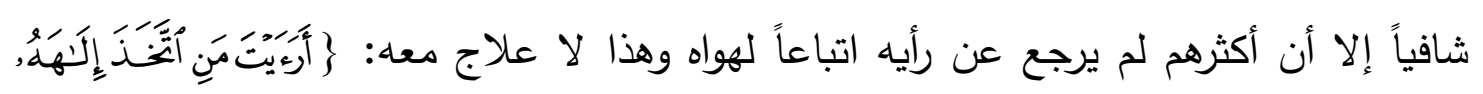

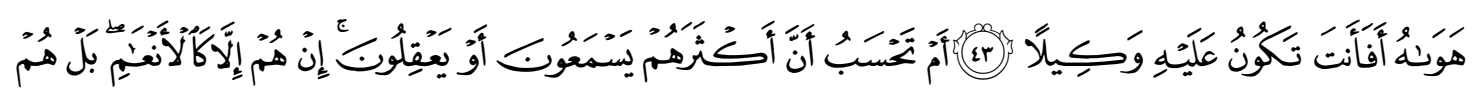

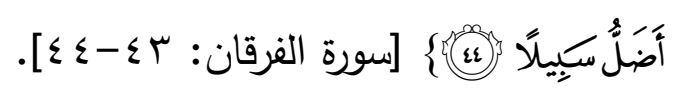




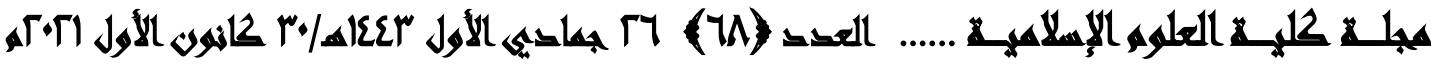

المبحث الثاني: حوار عبدالله بن الزبير ع مع الخوارج

لعبدالله بن الزبير محاورة طويلة مع الخوارج يحسن إيرادها لما فيها من دروس وعبر الفير وقيم مهمة: يقول ابن المبرد في الكامل: „ابلغ الخوارج خروج مسلم بن عقبة إلى الدينة وقتله أهل الحرّة،

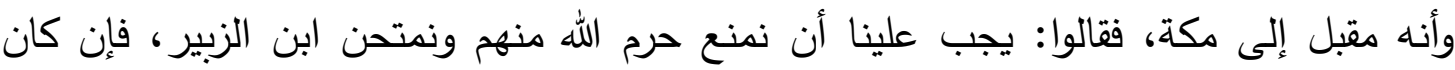

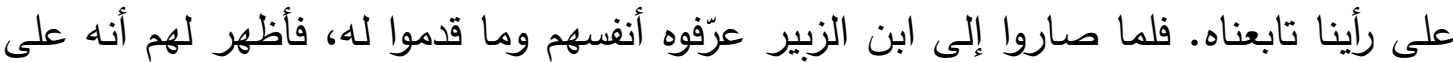

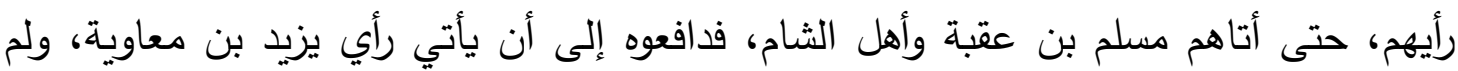

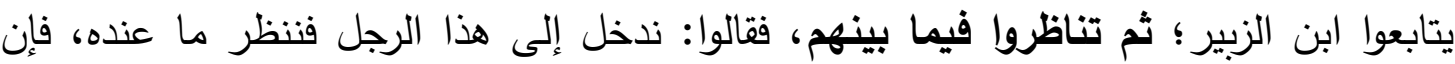
قدَّم أبا بكر وعمر وبرىء من عثمان وعليّ وكفَّر أباه وطلحة بايعناه؛ وإن تكن الأخرى ظهر لنا

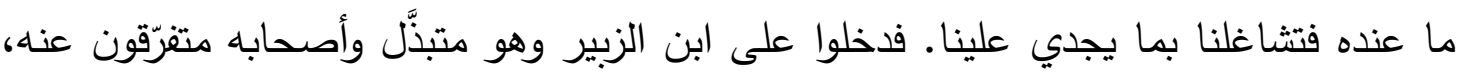

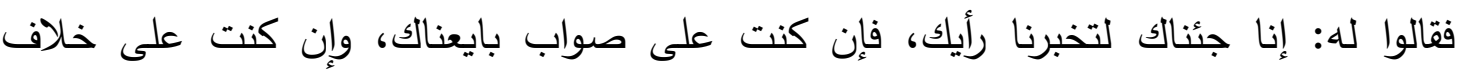

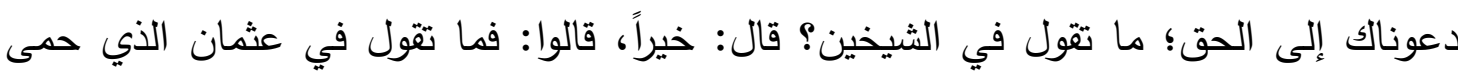

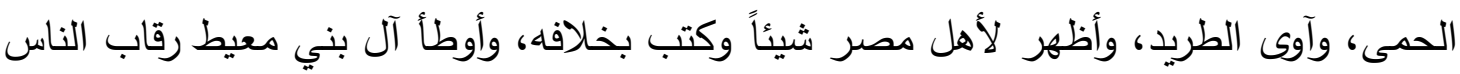
وآثرهم بفيء المسلمين، وفي الذي بعده الذي حكم الرجال في دين الله وأقام على ذلك غير كائ تائب

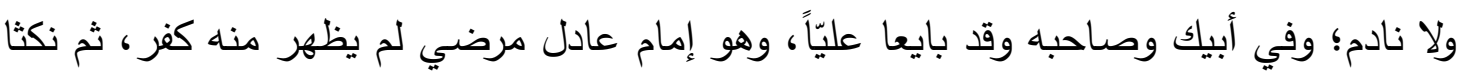

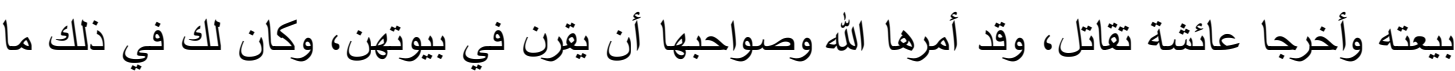

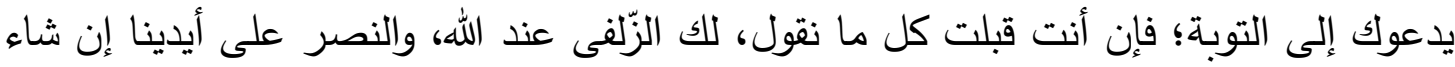
الله، ونسأل الله لك التوفيق، وإن أبيت خذلك الله وانتصر منك بأيدينا. فقال ابن الزبير : إن الله أمر -وله العزّة والقدرة- في مخاطبة أكفر الكافرين وأعتى العاتين بأرقّ بالئ من هذا القول؛ فقال لموسى وأخيه صلى الله عليهما:

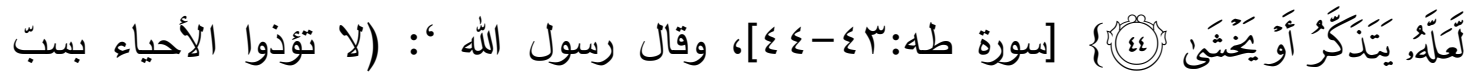

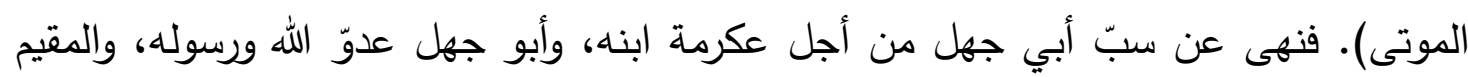

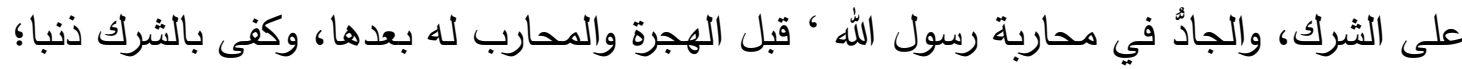




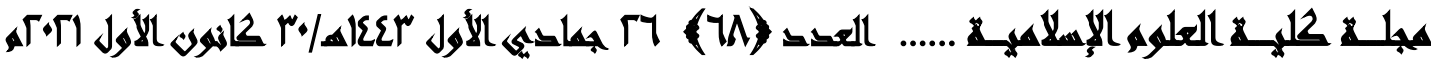

وقد كان يغنيكم عن هذا القول الذي سمّيتم فيه طلحة وأبي أن تقولوا: أتبرأ من الظالمين؟ فإن كانا منهم دخلا في غمار الناس، وان لم يكونا منهم لم تحفظوني بسبّ أبي وصاحبه، وأنتم

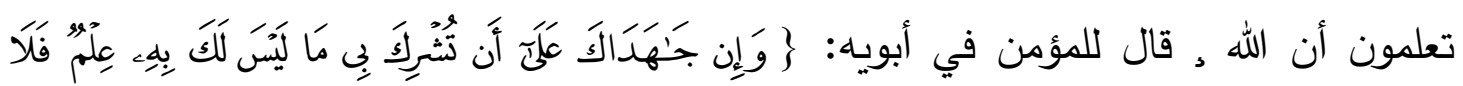

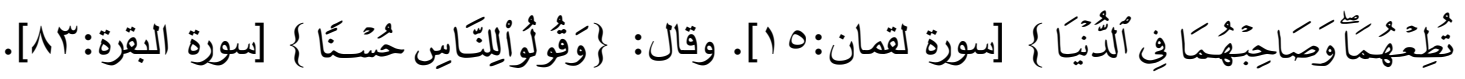
وهذا الذي دعوتم إليه أمر له ما بعده، وليس يقنعكم إلا التوقيف والتّصريح، ولعمري إنّ ذلك

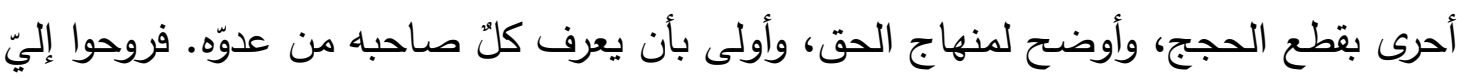
من عشيّتكم هذه أكثف لكم ما أنا عليه إن شاء الله تعالى. فلما كان العشي راحوا إليه، فخرج إليهم وقد لبس سلاحه، فلما رأى ذلك نجدة ، قال: هذا خروج منابذ لكم. فجلس على رفع من الأرض فحمد الله وأثنى عليه وصلى على نبيّه، ثم ذكر أبا بكر وعمر أحسن ذكر، ثم ذكر عثمان في السنين الأوائل من خلافته؛ ثم وصلهن بالسّنين التي أنكروا سيرته فيها فجعلها كالماضية، وأخبر أنه آوى الحكم بن أبي العاصي بإذن رسول الإن الله ، وذكر الحمى وما كان فيه من الصلاح، وأنّ القوم استعتبوه من أمور ما كان له أن يفعلها أولاً

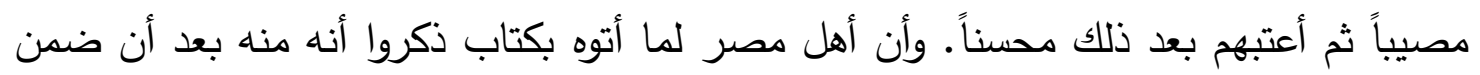
لهم العتبى ثم كتب ذلك الكتاب بقتلهم. فدفعوا الكتاب إليه، فحلف بالله أنه لم يكتبه ولم يأمر به؛ وقد أمر الله , بقبول اليمين ممن ليس له مثل سابقته، مع ما اجتمع له من صهر رسول لهابه

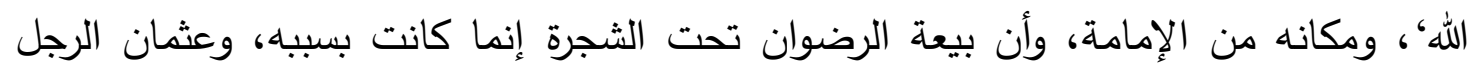
الذي لزمته يمين لو حلف عليها حلف على حق، فافتداها بمائة ألف ولم يحلف، وقد قال رسول الله “: المن حلف بالله فليصدق، ومن حلف بالله فليقبله(1) . وعثمان أمير المؤمنين كصاحبيه. وأنا وليّ وليّه وعدوّ عدوّه، وأبي وصاحبه صاحبا رسول الله ، ورسول الله يقول عن

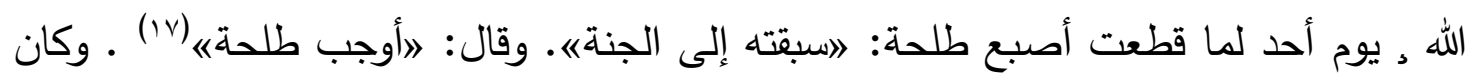
الصّديق إذا ذكر يوم أحد قال: ذلك يوم كله أو جلّه لطلحة. والزبير حواريّ رسول الله ،

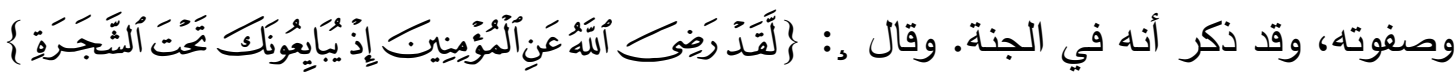




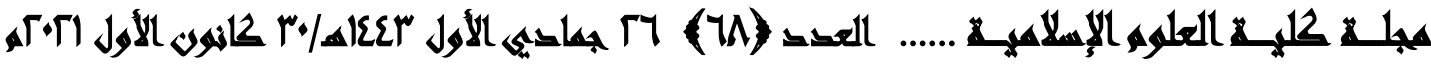

[سورة الفتح:^1]]. وما أخبرنا بعد أنه سخط عليهم؛ فإن يكن ما صنعوا حقًاً فأهل ذلك هم، وإن

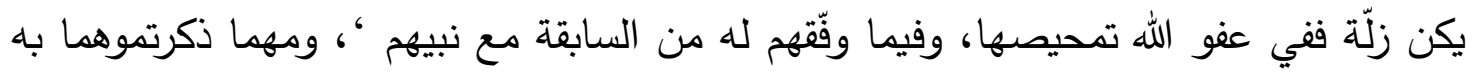

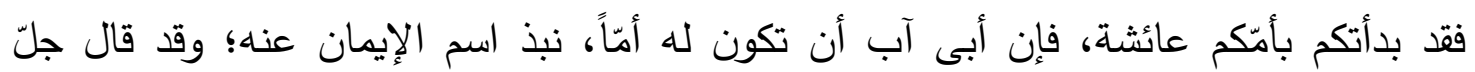
ذكره: بعض ثم انصرفوا عنهه| (1). وهذه المناظرة بين ابن الزبير والخوارج تبيّن كيف أن الحوار يكثف عوار الأفكار..

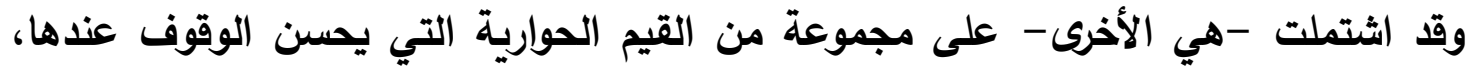
والتأمل فيها :

1- اختيار الوقت والمكان المناسب للمناظرة، وخصوصاً مع أمثال هؤلاء الذين عُرف عنهم ألها

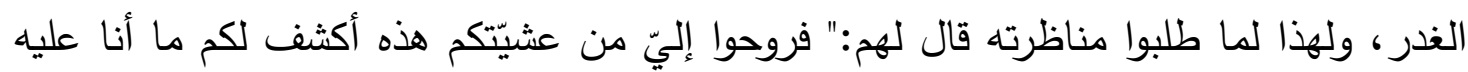

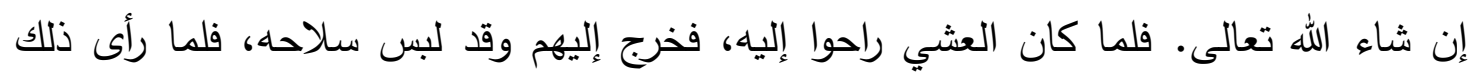
نجدة ، قال: هذا خروج منابذ لكم".

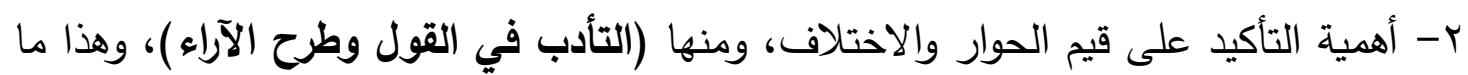
فعله ابن الزبير مع هؤلاء الخوارج لما تكلموا في كبار الصحابة بكلام لا يليق بمقامهر

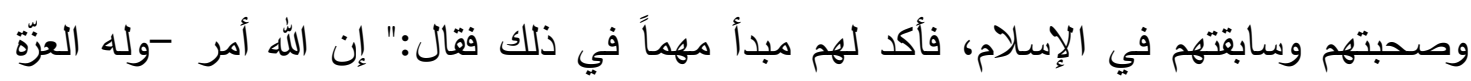

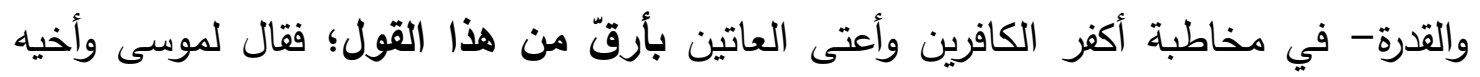

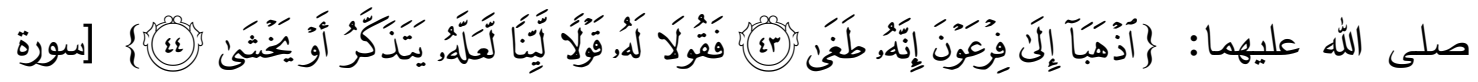

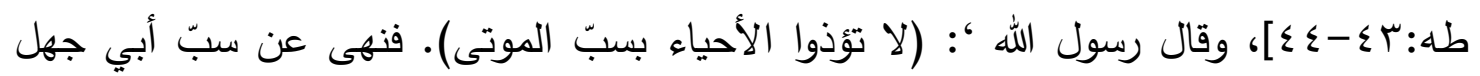

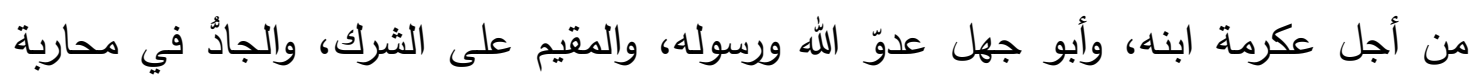
رسول الله ، قبل الهجرة والدحارب له بعدها، وكفى بالثرك ذنباً". 


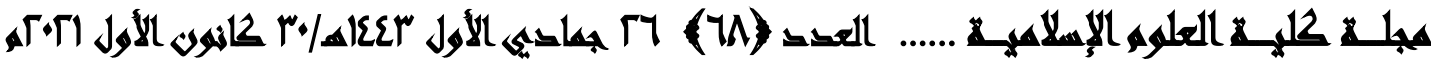

r- الصبر على جهل المحاور الآخر وتحمل خطأه، ويدل عليه أن ابن الزبير، وكان هو امير

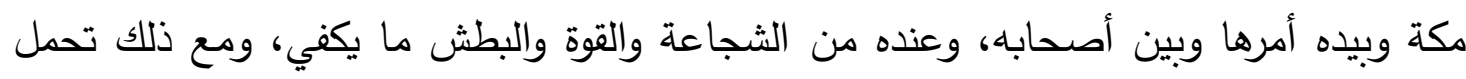

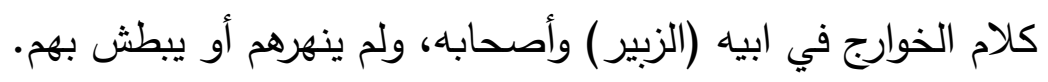
ع - أهمية أن يكون المناظر (عالماً قوي الحجة)، وهذا ظاهر في المناظرة، ويؤكد هذا أنه قال لهم:" وليس يقنعم إلا التوقيف والتّصريح، ولعمري إنّ ذلك أحرى بقطع الحجج، وأوضح

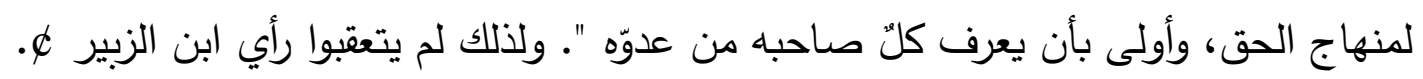

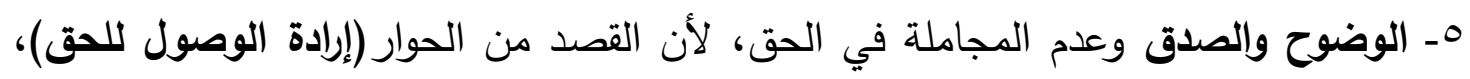
فالحق أحق أن يُتبع، فمع حاجة ابن الزبير ه الثديدة لهم، ورغبته في كونهم من جيشه، إلا أنه لهن

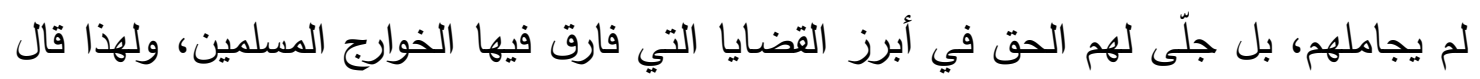

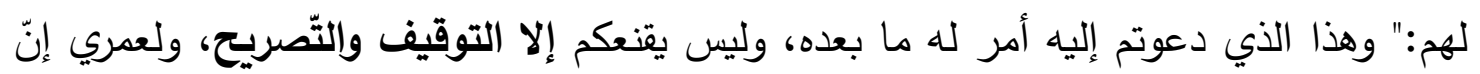
ذلك أحرى بقطع الحجج، وأوضح لهنهاج الحق، وأولى بأن يعرف كلٌ صاحبه من عدوّه". ثم أث أجابهر بما يعتقد ويدين الله به دون مجاملة أو مواربة. 7- أجاب ابن الزبير على جميع ما ذكروه في عثمان وطلحة والزبير ، وبيّن عذرهم فيه، وهذا يؤكد على قيمة دهمة وهي (احترام الخصم، وإرادة الحق في الحوار)، ومن احترامه الإجابة على تساؤلاته وشبهاته، ليصل الجميع على مقصود الحوار وهدفه وهو الوصول للحق وبيانه. V- أهمية معرفة المحاور بما سوف يحاور فيه: ولذلك لما تكلموا في عثمان وعلي والزبير وطلحة، أستحضر فضائل هؤلاء الواردة في حقهم في النصوص - كفضل أهل بيعة الرضوان وقصة طلحة في أحد..الخ- واعتبار سابقتهم في الإسلام وكذلك فضائلهم التي اشتملت عليها

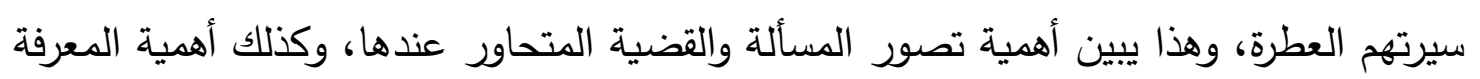
بالنصوص من الكتاب والسنة الدالة عليها وأنهما الفيصل عند الاختلاف، وكل هذا يعززه القيمة الحوارية المهمة(الاعتماد على الحجة). 


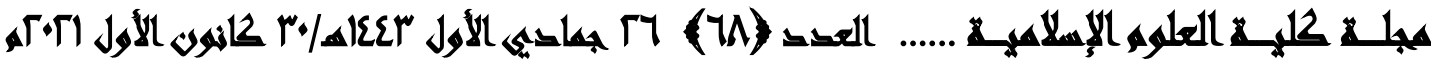

1- بسبب علم المحاور((ابن الزبير) وقوة حجته، وثقته بنفسه وما هو عليه من الحق، انقطع هؤلاء الخوارج عن المناظرة، ولم يستطيعوا ان يتعقبوا رأيه، وما كان منهم الا انصرفوا عنه» فنظر بعضهم إلى بعض ثم انصرفوا عنه/، ووقاه الله شرهم وكيدهم، وهذا يبين أن أفضل طريق لعلاج الأفكار الضالة والثبهة المنحرفة دفعها بالحجة والبيان والعلم، لا بالقوة واللجاج. ولذلك لم يعودوا هؤلاء على ابن الزبير، وكان هذا الحوار سبباً في حصانة أصحاب ابن الزبير من أفكار الخوارج، ولعل هذا هو السبب في أن جعل ابن الزبير المحاورة في مكان عام، يراه الناس ويسمعونه" فجلس على رفع من الأرض "، ومثل هذا ما حصل في مناظرة علي وابن ان عباس (رضي الله عنهم).

هذه أهم القيم والآداب المهمة المستنبطة من محاورة ابن الزبير للخوارج. 


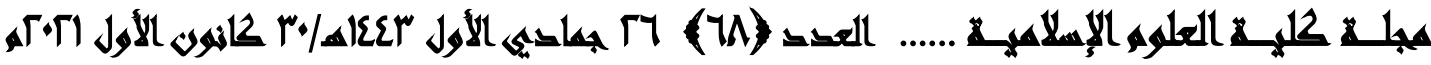

المبحث الثالث: حوارات أخرى للصحابة مع الخوارج

وهناك محاورات في بعض المسائل حصلت بين بعض الصحابة والخوارج كانت سبباً في رجوعهم عن رأيهم وخروجهم على الناس:

ومن ذلك محاورة جابر بن عبدالله للخوارج في مسألة خروج أهل الكبائر من النار .

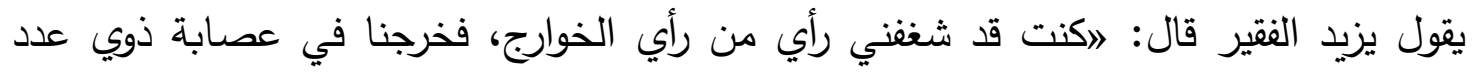

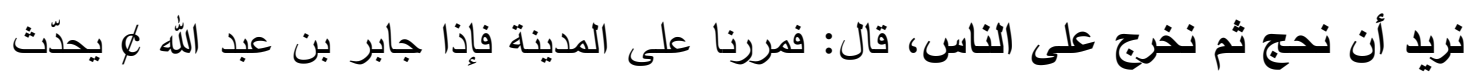

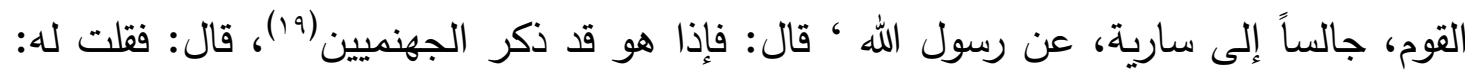

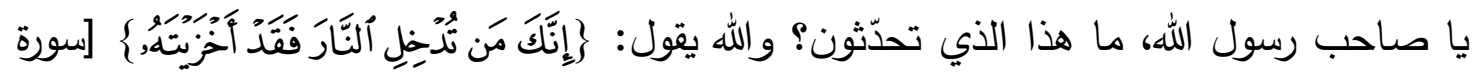

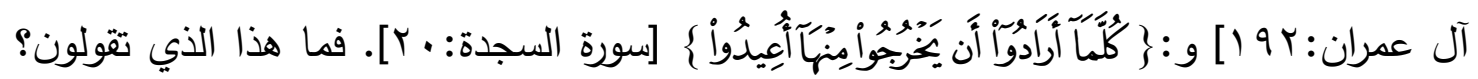
قال: فقال: أتقرأ القرآن؟ قلت: نعم، قال: فهل سمعت بمقام محمد '، يعني: الذي يبعثه الله فيه؟

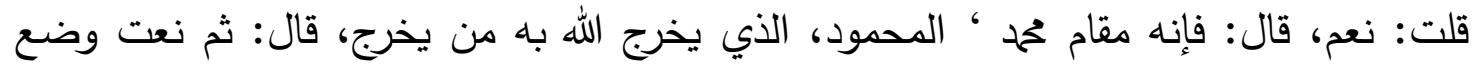

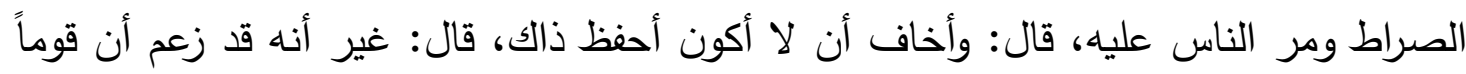

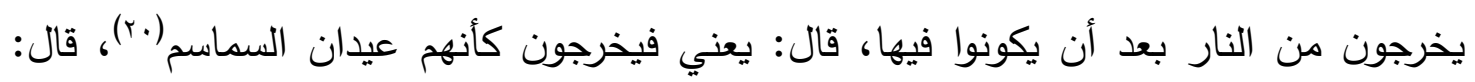

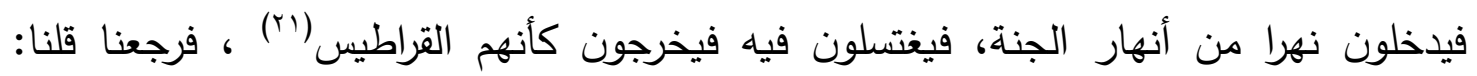

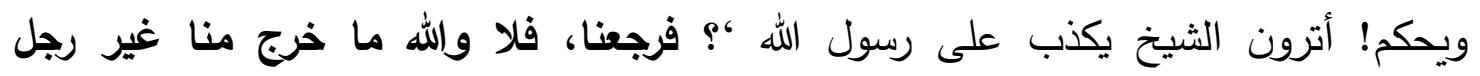

$$
\text { واحد《) }
$$

فهذه القصة اشتملت على دروس في الحوار ، أهمها:

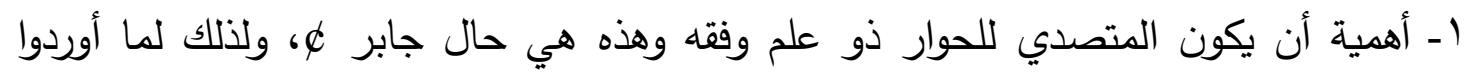

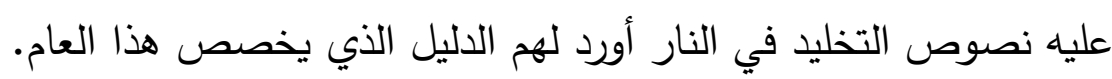

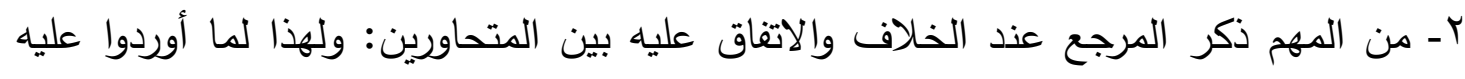

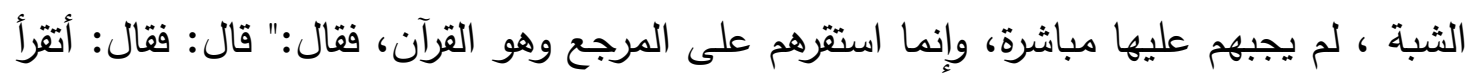




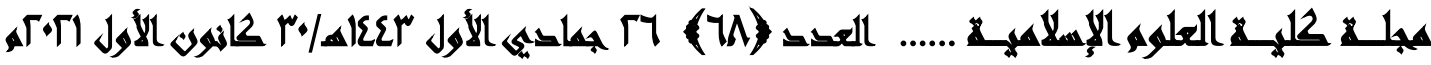

القرآن؟ قلت: نعم، قال: فهل سمعت بمقام ححمد '، يعني: الذي يبعثه الله فيه؟ قلت: نعم...". ثم بعد ذلك كثف ما عندهم من لبس. r- حُسن المحاورة وحُسن سماع الثبهة أدعى لقبول الخصم وقبول الجواب: وهذا ما حصل مع الخوارج، ولذلك رجع كلهم عن الخروج على المسلمين. ما سبق من آثار هي من باب المناظرة، وهناك أسلوب آخر استعمله الخوارج مع الصحابة وهو الأسئلة المتعنتة الذي يظهر من أصحابها قصد إحراج المسؤول أكثر من إرادة الحق، وقد تصدى لهم الصحابة (رضي الله عنهم) بالتي هي أحسن، ومن ذلك: ما رواه الضحالك بن مزاحم الهلالي قال: اخرج نافع بن الأزرق ونجدة بن عويمر في نفر من

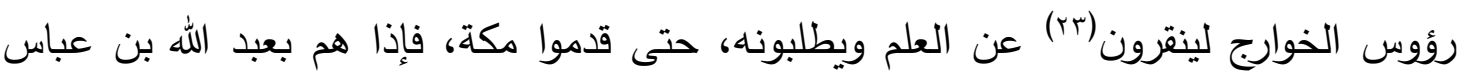

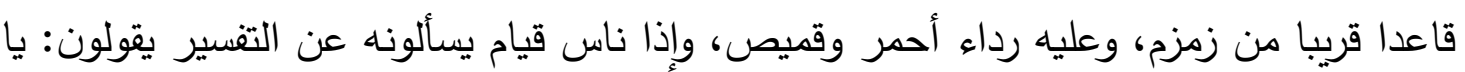
ابن عباس، ما تقول في كذا وكذا ؟ قال: هو كذا وكذا ، فقال له نافع بن الأزرق: ما أجرأك يا ابن عباس على ما تجريه منذ اليوم، فقال له ابن عباس: ثكلتك أمك يا نافع وعدمتك، ألا

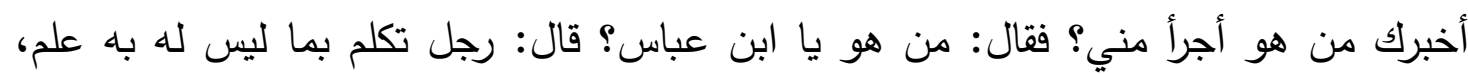

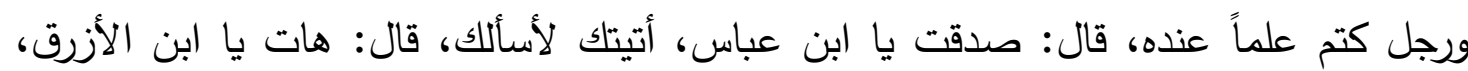
فسل.... فسأله نافع إحدى وثلاثين مسألة، في كل مسألة يطلب عليها شاهداً من كلام العرب، ثم يصدّقه على الجواب! وهذا يبين مدى التعنت في السؤال.

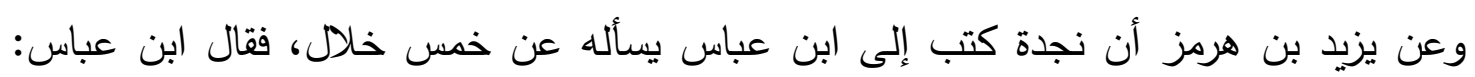

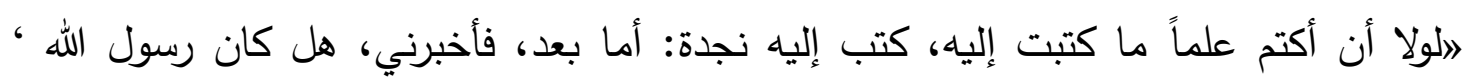
يغزو بالنساء؟ وهل كان يضرب لهن بسه؟ وهل كان يقتل الصبيان؟ ومتى ينقضي يتم اليتيم؟

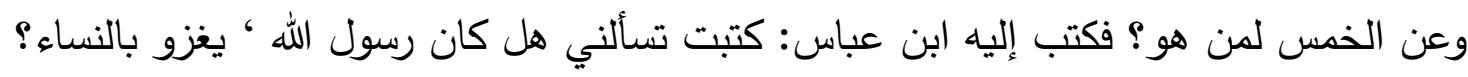
وقد كان يغزو بهن فيداوين الجرحى، ويحذين من الغنيمة، وأما بسهم، فلم يضرب لهن، وإن لهن 


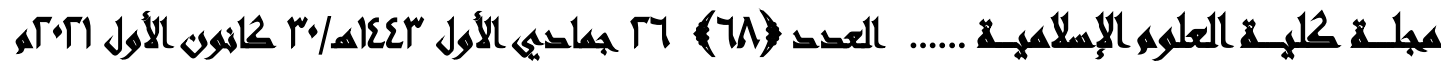

رسول الله ، لم يكن يقتل الصبيان، فلا تقتل الصبيان، وكتبت تسألني متى ينقضي يتم اليتيم؟

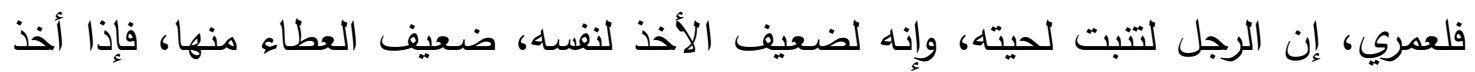
لنفسه من صالح ما يأخذ الناس فقد ذهب عنه اليتم، وكتبت تسألني عن الخمس: لمن هو؟ وإنا

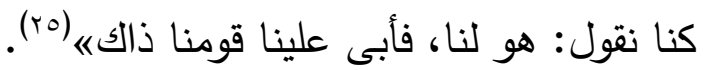




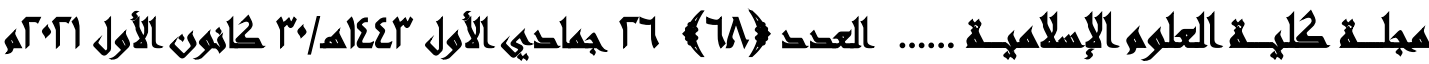

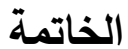

الحمد لله والصلاة والسلام على رسول الله وبعد

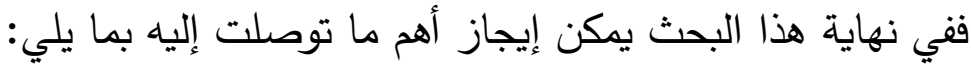
ا- من الأمور المستقرة التي لا خلاف فيها أن الصحابة أجمعوا على انحراف مسلك الخوارج، ولذلك أجمعوا على منابذة مذهبهم. r- أن الصحابة كانت لهم مواقف علمية وعملية تجاه هذا الانحراف. r- من أبرز هذه المواقف محاورة الخوارج وبيان فساد مذهبهم وضلالهه.

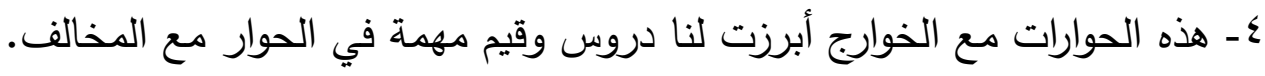

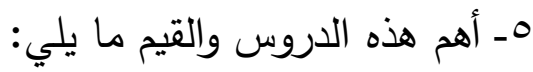
- حسن اختيار المحاور شكلاً ومضموناً.

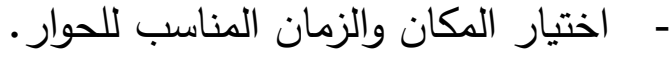
- أن يكون المحاور على جانب من العلم وحسن الجدل. - - أن يكون عارفاً وملماً بالمسألة والقضية محل الحوار على العلى وجه الخصوص. - علي المحاور بالصبر وطول البال حتى يمتص ردة فعل الخصم. - تحديد أرضية مشتركة بين المتحاورين يرجعون إليها في الحوار . - - استيعاب الثبه المثارة من الخصم قدر الاستطاعة.

- ليس بالضرورة رجوع الخصم إلى جادة الصواب- وإن كان هذا أحد أهداف الحوار المهمةلكن معذرة إلى ربكم ولعلهم يتقون. 7- من خلال البحث تبين لنا أثر الحوار مع المخالف في رد بدعته، وكفِّ شره وأذاه عن المسلمين، وهذه نتيجة مهمة للحوار مع أهل الضلال.

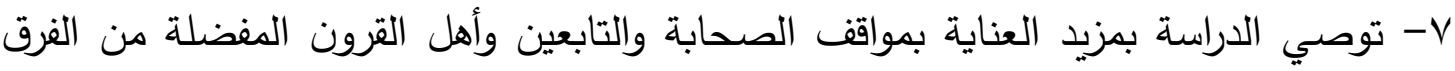

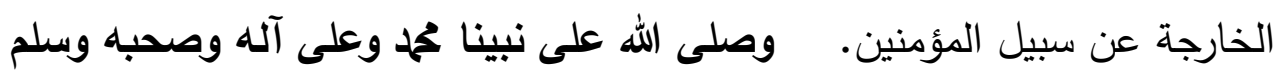




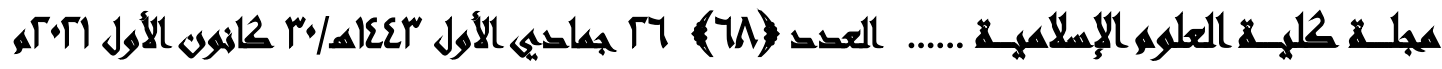

\section{هوامش البحث}

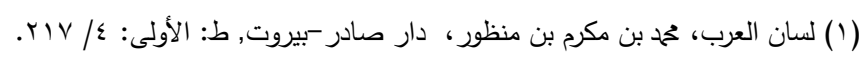

(ץ) جمهة اللغة، أبو بكر بن دريد الأزدي، ت: رمزي منير بعلبكي، الناشر: دار العلم للملايين، بيروت، الطعة: الأولى : / مبه (ז) القاموس المحيط، محم بن يعقوب الفيروآبادي، ت: مكتب تحقيق التراث في مؤسسة الرسالة, مؤسسة الرسالة, ط: الثامنة، بيروت:

( ) آداب الحوار من خلال سيرة مصعب بن عمير، عدنان الجابري، الناشر : دار الأوراق الثقافية، الطبعة: الأولى: صه (0) آداب الحوار وقواعد الاختلاف، المؤلف: عمر بن عبد الله كامل،الناشر : الكتاب منشور على موقع وزارة الأوقاف السعودية بدون

$$
\text { بيانات: ص؛ }
$$

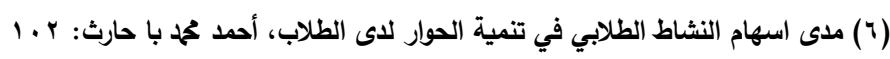

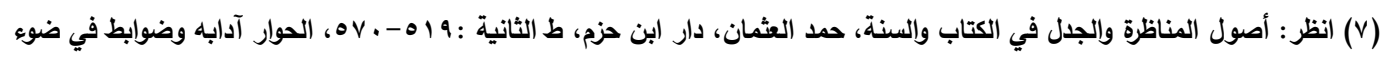

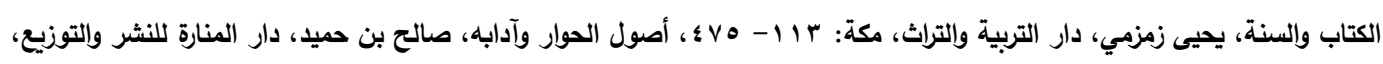

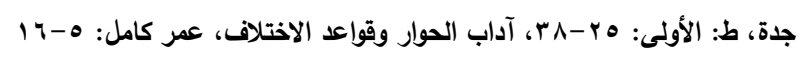

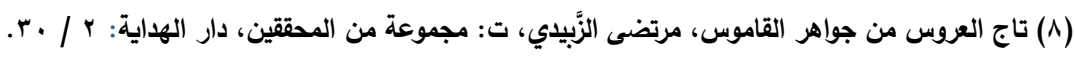

(9) مقالات الإسلاميين و اختلاف المصلين، أبو الحسن الأشعري، غنى بتصحيحه: هلموت ريتر، الناشر: دار فرانز شتايز، الطبعة:

الثاثلة:

( • (1) مجموع الفتاوى، ابن تيمية، جمع وترتيب ابن قاسم، طبعة وزارة الشئون الإسلامية.: با/Tr.

(1') ويقصد بحملة القرآن الخوارج فإنه كان يطلق عليهم في زمن علي ب(القراء).

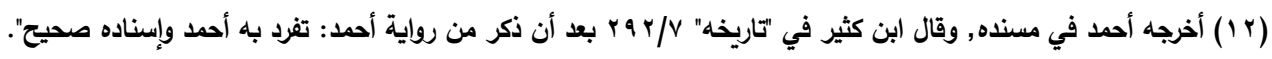

(ril) أي متغيرة. انظر: النهاية في غريب الحديث والأثر، ابن الأثير، ت: طاهر أحمد الزاوى، محمود محم الطناحي، المكتبة العلمية -

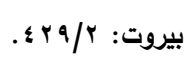




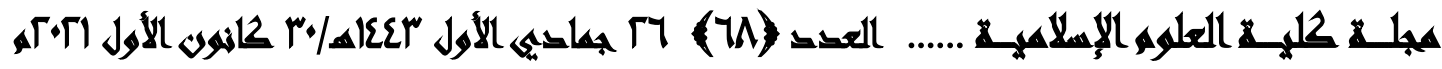

(؛ ) أي تشهر لهم بكثرة الصلاة مما يظهر عليها من الخشونة بسبب ملامسة الأرض, ويشه لذلك الرواية الأخرى:اكأن أيديهم وركبهم ثفنه, "والثفنة: ما ولي الأرض من كل ذات أربع إذا بركت، كالركبتين وغيرهما، ويحصل فيه غلظ من أثر البروك" ولذلك كان يقال لكبيرهم

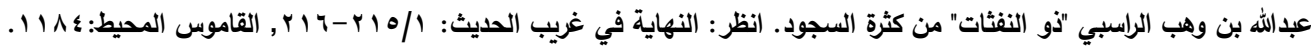

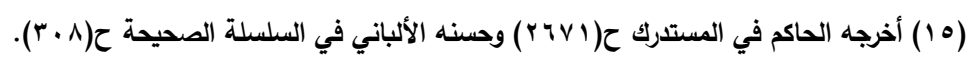

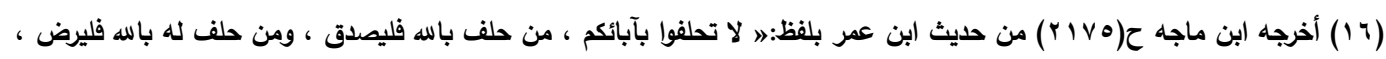

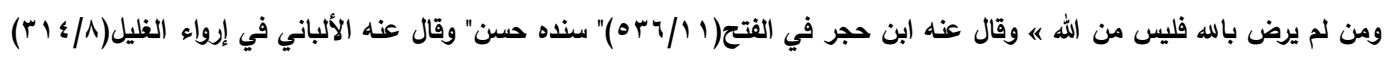

إسناده صحيح.

(1V) أخرجه الترمذي في جامعه ح(ه . 1 ) بلفظ:» كان على النبي ، درعان يوم أحد ، فنهض إلى الصخرة فلم يستطع ، فأقعد طلحة تحته فصد النبي ، عليه حتى استوى على الصخرة. فقال: سمعت النبي ، يقول: أوجب طلحةه وقال عنه الألباني في الصحيحة تحت رقم) ؛ 9 (9 ) "حديث حسن".

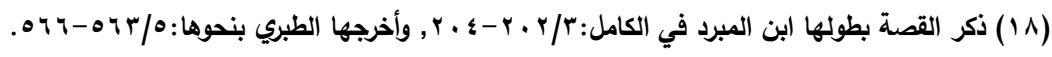

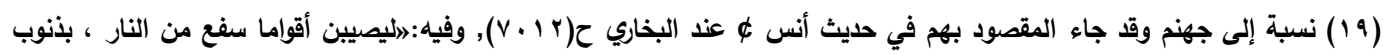
أصابوها عقوبة ، ثم يلخلهم الله الجنة بفضل رحمته ، يقال لهم: الجهنميونه. (r· (r) السماسم جمع سمسم، وعيدانه تراها إذا قلعت وتركت ليؤذ حبها دقاقا سودا كأنها محترقة، فثبه بها هؤلاء الذين يخرجون من النار وقد امتحشوا. انظر : النهاية في غريب الحليث: ؟/ . . ؛. (Y) القراطيس جمع قرطاس, وهو الصحيفة التي يكتب فيها, شبههم بالقراطيس لثدة بياضهم بعد اغتسالهم وزوال ما كان عليهم من السواد. انظر: المنهاج شرح صحيح مسلم بن الحجاج، أبو زكريا النووي، دار إحياء التراث العبي-بيروت، ط: الثانية: ب/ ؟ه.

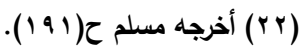

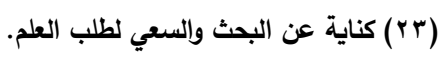

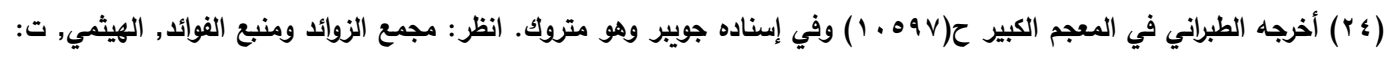

حسام الدين القدسي, مكتبة القدسي-القاهرة:( ا / ؛ ؛ ).

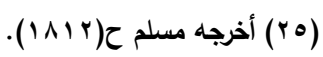




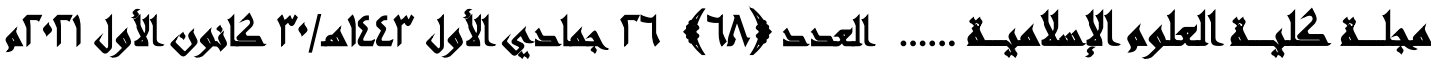

\section{المصادر والمراجع}

ـ آداب الحوار من خلال سيرة مصعب بن عمير ،المؤلف: عدنان بن سليمان بن مسعد الجابري، راجعه

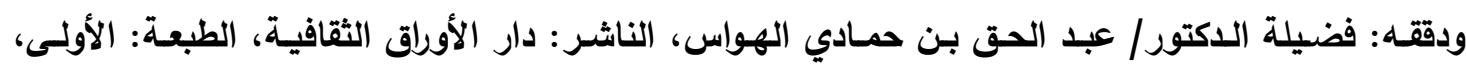

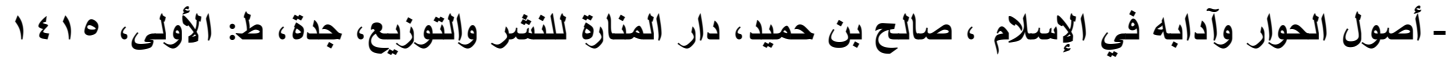

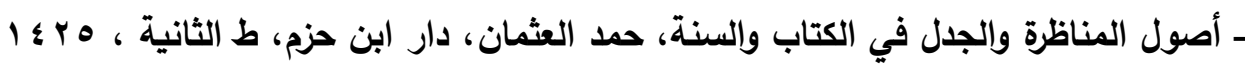

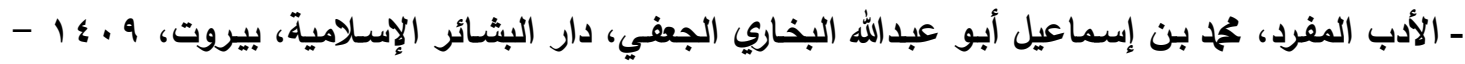

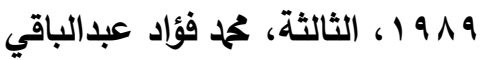
- الحوار: آدابه وضوابط في ضوء الكتاب والسنة، يحيى زمزمي، رسالة ماجستير، دار التربية والتراث، مكة،

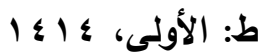
- القاموس المحيط، كحم بن يعقوب الفيروزآبادي، ت: مكتب تحقيق التراث في مؤسسة الرسالة, مؤسسة

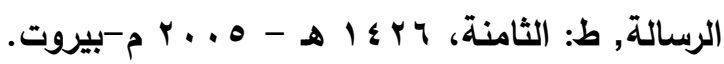
ـ الكامل في اللغة والأدب، محمد بن يزيد المبرد، ت: محمد أبو الفضل إبراهيم، الناشر: دار الفكر العربي -

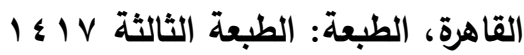
- الملل والنحل، محمد بن عبدالكريم الثهرستاني، ت: المحل الفاضلي، المكتبة العصرية، بيروت، ط: الثانية، $1 \leqslant r \mid$

- غريب الحديث، أبو عُبيد القاسم بن سلاّم، ت: محمل عبد المعيد خان، مطبعة دائرة المعارف العثمانية، حيدر

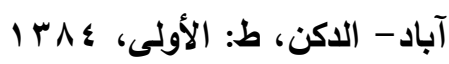

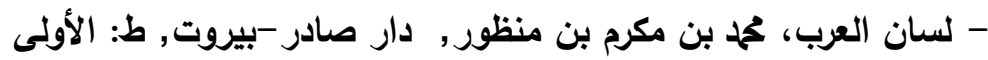

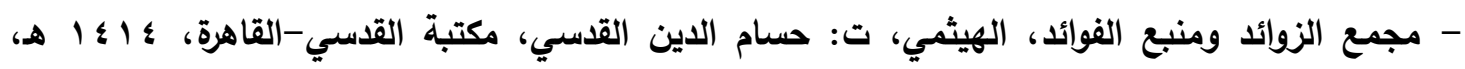
م $199 \varepsilon$

- آداب الحوار وقواعد الاختلاف، المؤلف: عمر بن عبد الله كامل،الناشر : الكتاب منشور على موقع وزارة الأوقاف السعودية بدون بيانات -إرواء الغليل في تخريج أحاديث منار السبيل، محمد ناصر الدين الألباني، إثراف: زهير الثـاويش، المكتب

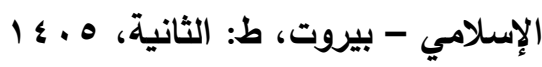




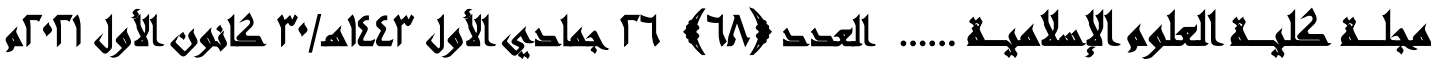

-الاستذكار، ابـن عبدالبر، ت: سـالم عحمد عطا وعحم علي معوض، دار الكتب العلمية، بيروت، ط: الأولى،

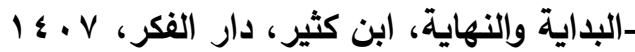

-الزهد لأبي داود، سليمان بن الأثعث السِِِّنْتاني، ت: ياسر بن ابراهيم بن عحم، أبو بـلال غنيم بن عباس بن غنيم وقدم لله وراجعه: فضيلة الشيخ تحم عمرو بن عبد اللطيف، الناشر: دار المشكاة للنشر والتوزيع،

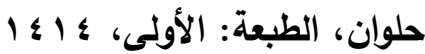
-السنن الكبرى، أحمد بن شعيب أبو عبد الرحمن النسائي، دار الكتب العلمية، ت: د. عبد الغفار سليمان

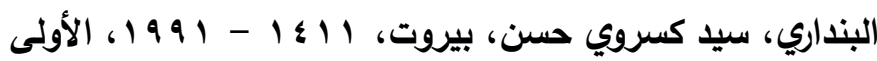
-السيرة النبوية لابن هشام، ت: عبد الملك بن هشام المعافري، ت: مصطفى السقا وإبراهيم الأبياري وعبد الحفيظ الشـلبي، الناشـر: شـركة مكتبـة ومطبعة مصطفى البابي الحلبـي وأولاده بمصـر، الطبعـة: الثانيـة، م 1900- 1 irvo

-الطبقات الكبرى، ابن سعد، ت: إحسان عباس، دار صادر - بيروت، الطبعة: الأولى، 19 19 م. -الكامل في التاريخ، أبو الحسن علي بن أبي الكرم عحم بن محمد الجزري، عز الدين ابن الأثير، ت: عمر عبد

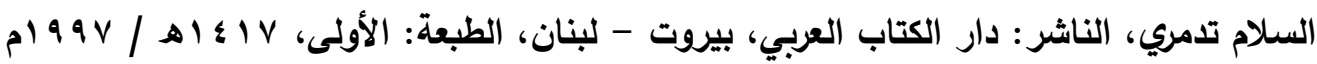
-المجتبى من السنن،، أحمد بن شعيب أبو عبد الرحمن النسائي، ت: عبدالفتاح أبو غدة، مكتب المطبوعات

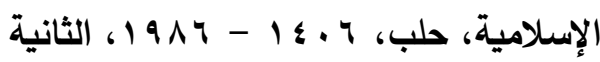
-المستدرك على الصحيحين، محمد بن عبدالله أبو عبدالله الحاكم النيسـابوري، ت: مصطفى عبد القادر عطا،

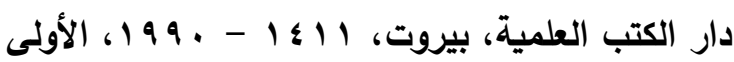
-المسند، أحمد بن ححمد بن حنبل، ت: شعيب الأرنؤوط - عادل مرشد، وآخرون، الناشر : مؤسسـة الرسـالة،

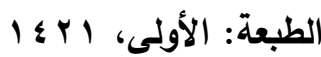
-المطالب العاليـة بزوائـد المسـانيد الثمانيـة، ابن حجر العسقلاني، ت: (VV) رسـالة علمية قدمت لجامعة

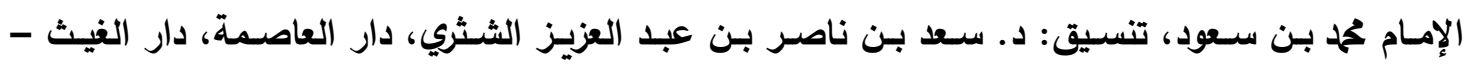
السعودية، ط: الأولى، 19 -المعجم الأوسط، أبو القاسم سليمان بن أحمد الطبراني، ت: طارق بن عوض الله بن عحم، عبد المحسن بن

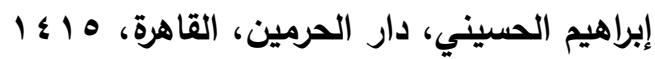




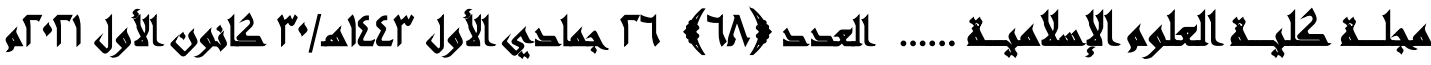

-المعجم الكبير، سليمان بن أحمد بن أيوب أبو القاسم الطبراني، مكتبة العلوم والحكم، الموصل، ؛ ـ ـ1 ـ

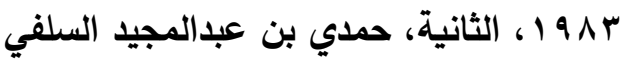
-المنهاج شرح صحيح مسلم بن الحجاج، أبو زكريا النووي، دار إحياء التراث العربي-بيروت، ط: الثانية، .1 rar

-النهاية في غريب الحديث والأثر، ابن الأثير، ت: طاهر أحمد الزاوى، محمود محمد الطناحي، المكتبة العلمية

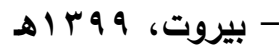

-تاج العروس من جواهر القاموس، مرتضى الزَّبيدي، ت: مجموعة من المحققين، دار الهداية.

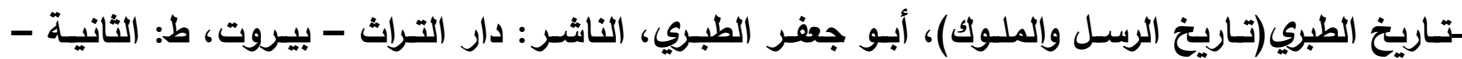
SI $\mathrm{H} \wedge \mathrm{V}$

-تاريخ بغداد، أحمد بن علي أبو بكر الخطيب البغدادي، دار الكتب العلمية-بيروت.

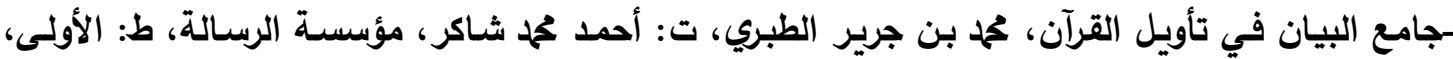
$1 \varepsilon Y$

- جمهرة اللغة، أبو بكر بن دريد الأزدي، ت: رمزي منير بعلبكي، الناشر: دار العلم للملايين، بيروت،

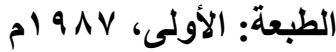
-سلسلة الأحاديث الصحيحة، أبو عبد الرحمن محمد ناصر الدين الألباني، الناشر : مكتبة المعارف للنشر

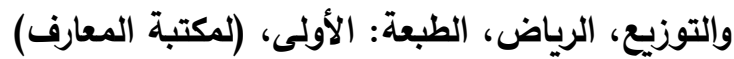

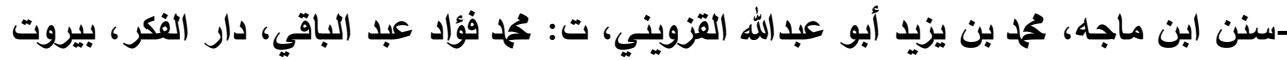

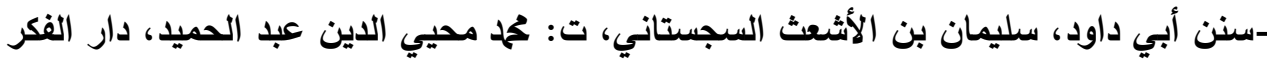

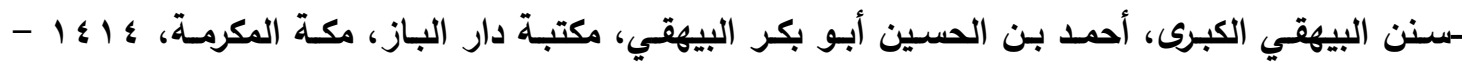
؛ 99 1،، تحمة عبد القادر عطا سنن البيهقي الكبرى، أحمد بن الحسين بن علي بن موسى أبو بكر البيهقي، ت: عمحم عبد القادر عطا،

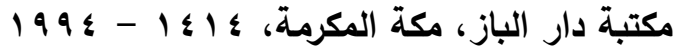
سنن الترمذي، محمل بن عيسى أبو عيسى الترمذي، ت: أحمد محمد شاكر وآخرون، دار إحياء التراث العربي، بيروت -سنن الدارمي، عبدالله بن عبدالرحمن أبو محمد الدارمي، ت: فواز أحمد زمرلي، خالد السبع، دار الكتاب

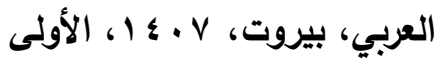




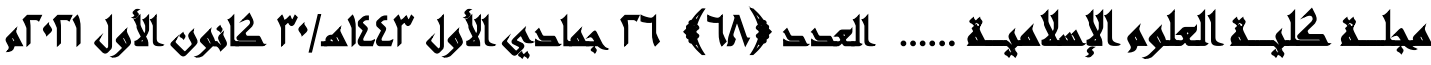

-صحيح البخاري (الجامع الصحيح المختصر)، محم بن إسماعيل البخاري، ت: د. مصطفى ديب البغا الناشر:

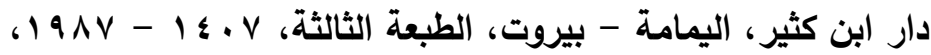

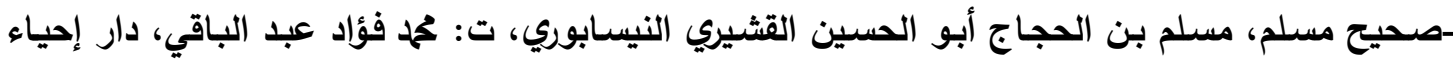
التراث العبي، بيروت -غريب الحديث، إبراهيم بـن إسـاق الحربي، ت: سليمان إبراهيم تحما العايد، الناشر : جامعة أم القرى،

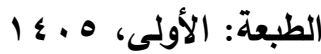
ـفتح الباري شرح صحيح البخاري، ابن حجر العسقلاني، ت: عحم فؤاد عبد الباقي، دار المعرفة - بيروت، I rva -كتاب السنة (ومعه ظلال الجنة في تخريج السنة بقلم: محمد ناصر الدين الألباني)، أبو بكر بن أبي عاصم،

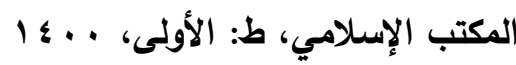
-كتاب الفتن، أبو عبد الله نعيم بن حمـاد، تالت سمير أمين الزهيري، الناشـر : مكتبة التوحيد - القـاهرة،

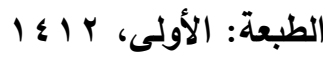
-لسان الميزان، ابن حجر العسقلاني، دائرة المعرف النظامية - الهند، الناشر : مؤسسة الأعلمي للمطبوعات

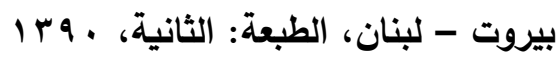
-مجموع الفتاوى، ابن تيمية، جمع وترتيب ابن قاسم، طبعة وزارة الثئون الإسلامية.

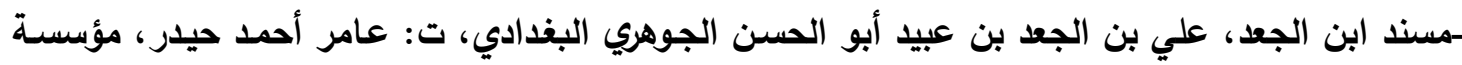

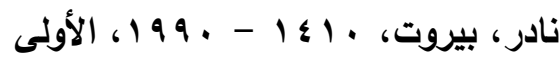
-مسند أبي يعلى، أحمد بن علي بن المثنى أبو يعلى الموصلي التميمي، ت : حسين سليم أسد، دار المأمون

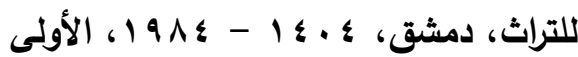
-مصنف ابن ابي شيبة، أبو بكر عبد الله بن محم بن أبي شيبة الكوفي، ت: كمال يوسف الحوت، مكتبة

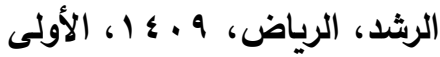
-مصنف عبدالرزلق الصنعاني، أبو بكر عبد الرزاق بن همام الصنعاني، ت: الريب، حبي الرحمن الأعظمي، المكتب

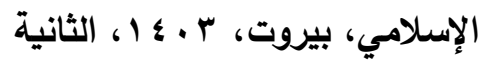
-مقالات الإسلاميين و اختلاف المصلين، أبو الحسن الأثشعي، عنى بتصحيحه: هلموت ريتر، الناشر: دار

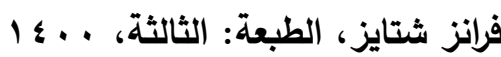




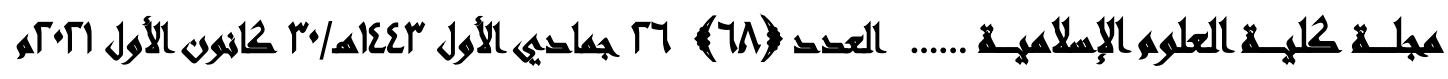

-منهاج السنة النبويـة في نقض كـلام الشيعة القدريـة، ابن تيمية، ت: عحمد رشـاد سـالم، جامعة الإمـام، ط: الأولى، 7 . -موطأ الإمـام مالك -، مالك بن أنس أبو عبدالله الأصبحي، ت: عحم فؤاد عبد الباقي، دار إحياء التراث

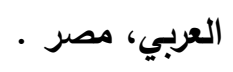




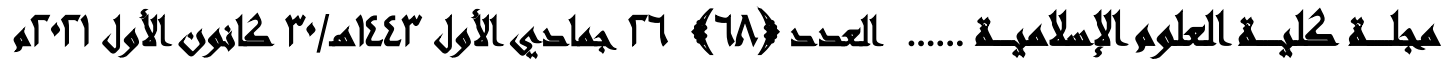

Sources and references

- The etiquette of dialogue through the biography of Musab bin Omair, the author: Adnan bin Suleiman bin Massad Al-Jabri, reviewed and revised by: His Eminence Dr. Abdul Haq bin Hammadi Al-Hawas, Publisher: Dar AlAwraq Al-Thaqafia, Edition: First, 1435

- The Origins of Dialogue and Its Etiquette in Islam, Saleh bin Hamid, Dar AlManara for Publishing and Distribution, Jeddah, I: First, 1415

The Origins of Debate and Controversy in the Book and the Sunnah, Hamad Al-Othman, Dar Ibn Hazm, Second Edition, 1425

- Single Literature, Muhammad bin Ismail Abu Abdullah Al-Bukhari Al-Jaafi, Dar Al-Bashaer Al-Islamiyyah, Beirut, 1409 - 1989, third, Muhammad Fouad Abdel-Baqi

- Dialogue: Its Etiquette and Controls in the Light of the Qur'an and Sunnah, Yahya Zamzami, Master's Thesis, House of Education and Heritage, Mecca, I: First, 1414

- The Ocean Dictionary, Muhammad bin Yaqoub Al-Fayrouzabadi, t.: The Heritage Investigation Office at the Al-Resala Foundation, Al-Resala Foundation, i.: Eighth, 1426 AH - 2005 AD - Beirut.

- Al-Kamel in Language and Literature, Muhammad Bin Yazid Al-Mubarrad, T: Muhammad Abu Al-Fadl Ibrahim, Publisher: Dar Al-Fikr Al-Arabi - Cairo, Edition: Third Edition 1417

- Al-Malal and Al-Nahl, Muhammad bin Abdul-Karim Al-Shahristani, T: Muhammad Al-Fadli, Al-Mataba Al-Asriyya, Beirut, Edition: II, 1421 . 


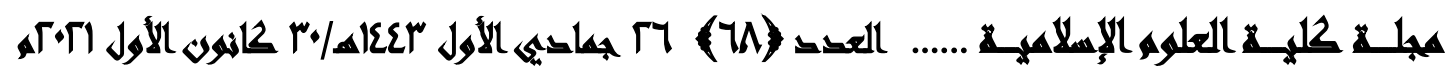

- Gharib al-Hadith, Abu Obaid al-Qasim bin Salam, t.: Muhammad Abd alMa'id Khan, Ottoman Encyclopedia Press, Hyderabad - Deccan, i: First, 1384 - Lisan al-Arab, Muhammad bin Makram bin Manzur, Dar Sader - Beirut, i: the first

- Majma' al-Zawa'id and the Source of Benefits, Al-Haythami, $t$ : Hussam AlDin Al-Qudsi, Al-Qudsi Library - Cairo, 1414 AH, 1994 AD

- The Etiquette of Dialogue and the Rules of Difference, Author: Omar bin Abdullah Kamel, Publisher: The book is published on the website of the Saudi Ministry of Endowments without data.

- Irwa Al-Ghalil in the Graduation of the Hadiths of Manar Al-Sabil, Muhammad Nasir Al-Din Al-Albani, Supervision: Zuhair Al-Shawish, The Islamic Office - Beirut, i: II, 1405

-The Istikhara, Ibn Abd al-Bar, T: Salem Muhammad Atta and Muhammad Ali Moawad, Dar al-Kutub al-IImiyya, Beirut, I: First, 1421.

-The Beginning and the End, Ibn Kathir, Dar Al-Fikr, 1407

Al-Zuhd by Abu Dawood, Suleiman bin Al-Ash'ath Al-Sijistani, T.: Yasser bin Ibrahim bin Muhammad, Abu Bilal Ghoneim bin Abbas bin Ghunaim, and presented to him and reviewed by: Sheikh Muhammad Amr bin Abdul Latif, Publisher: Dar Al-Mishkat for Publishing and Distribution, Helwan, Edition: First, 1414

- Al-Sunan Al-Kubra, Ahmed bin Shuaib Abu Abdul Rahman Al-Nasa'i, Dar Al-Kutub Al-Ilmia, t.: d. Abd al-Ghaffar Suleiman al-Bandari, Sayed Kasravi Hassan, Beirut, 1411 - 1991, the first

- Biography of the Prophet by Ibn Hisham, t.: Abd al-Malik ibn Hisham alMa'afry, t.: Mustafa al-Saqa, Ibrahim al-Abyari and Abd al-Hafiz al-Shalabi, 


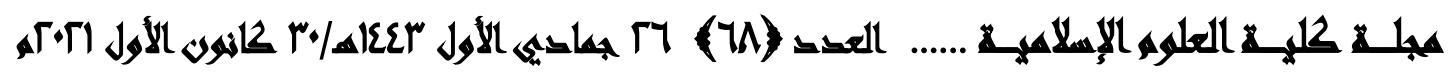

Publisher: Mustafa al-Babi al-Halabi and Sons Library and Press Company in Egypt, Edition: Second, 1375 AH - 1955 AD

- Al-Tabaqat Al-Kubra, Ibn Saad, T: Ihsan Abbas, Dar Sader - Beirut, Edition: First, 1968 AD.

- Al-Kamel fi Al-Tarikh, Abu Al-Hasan Ali bin Abi Al-Karam, Muhammad bin Muhammad Al-Jazari, Izz Al-Din Ibn Al-Atheer, T: Omar Abdel Salam Tadmuri, Publisher: Dar Al-Kitab Al-Arabi, Beirut - Lebanon, Edition: First, 1417 AH / 1997 AD

- Al-Mujtaba from Al-Sunan, Ahmed bin Shuaib Abu Abdul Rahman AlNasa'i, t.: Abdel Fattah Abu Ghuddah, Islamic Publications Office, Aleppo, 1406 - 1986, second

- Al-Mustadrak on the Two Sahihs, Muhammad bin Abdullah Abu Abdullah Al-Hakim Al-Naysaburi, T: Mustafa Abdel-Qader Atta, Dar Al-Kutub AlIImiyya, Beirut, 1411 - 1990, first

-Al-Musnad, Ahmed bin Muhammad bin Hanbal, T.: Shuaib Al-Arnaout Adel Murshid, and others, Publisher: Al-Resala Foundation, Edition: First, 1421

- The High Demands for the Eight Supplements of the Musnads, Ibn Hajar Al-Asqalani, T: (17) a scientific thesis submitted to the University of Imam Muhammad bin Saud, coordinated by: Dr. Saad bin Nasser bin Abdulaziz AlShathri, Dar Al-Asima, Dar Al-Ghaith - Saudi Arabia, Edition: First, 1419.

-The Middle Dictionary, Abu al-Qasim Suleiman bin Ahmed al-Tabarani, t: Tariq bin Awad Allah bin Muhammad, Abdul Mohsen bin Ibrahim Al-Husseini, Dar Al-Haramain, Cairo, 1415 


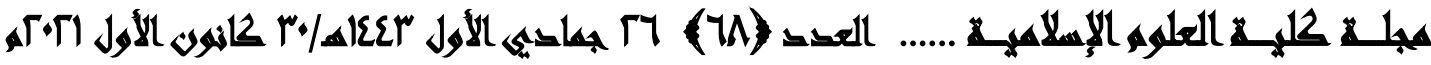

- The Great Lexicon, Suleiman bin Ahmed bin Ayyub Abu al-Qasim alTabarani, Library of Science and Judgment, Mosul, 1404 - 1983, second, Hamdi bin Abd al-Majid al-Salafi.

Al-Minhaj Sharh Sahih Muslim bin Al-Hajjaj, Abu Zakaria Al-Nawawi, House of Revival of Arab Heritage - Beirut, Edition: II, 1392.

- The End in Gharib Hadith and Athar, Ibn Al-Atheer, T: Taher Ahmad AlZawi, Mahmoud Muhammad Al-Tanahi, Scientific Library - Beirut, 1399 AH

- The crown of the bride from the jewels of the dictionary, Mortada AlZubaidi, $\mathrm{t}$ : A group of investigators, Dar Al-Hedaya.

- Tarikh al-Tabari (The History of the Messengers and Kings), Abu Jaafar alTabari, publisher: Dar al-Turath - Beirut, i: the second - $1387 \mathrm{AH}$

- History of Baghdad, Ahmed bin Ali Abu Bakr al-Khatib al-Baghdadi, Dar al-Kutub al-Ilmiyya - Beirut.

- Jami' al-Bayan fi Ta'wil al-Qur'an, Muhammad bin Jarir al-Tabari, t.: Ahmed Muhammad Shakir, Al-Resala Foundation, ed: First, 1420

- Jamharat Al-Lughah, Abu Bakr bin Duraid Al-Azdi, T.: Ramzi Mounir Baalbaki, Publisher: Dar AI-IIm for Millions, Beirut, Edition: First, 1987 AD

- Series of Sahih Hadiths, Abu Abd al-Rahman Muhammad Nasir al-Din alAlbani, Publisher: Al-Maaref Library for Publishing and Distribution, Riyadh, Edition: First, (to the Knowledge Library)

- Sunan Ibn Majah, Muhammad bin Yazid Abu Abdullah Al-Qazwini, t: Muhammad Fouad Abdel-Baqi, Dar Al-Fikr, Beirut

- Sunan Abi Dawood, Suleiman bin Al-Ash'ath Al-Sijistani, t.: Muhammad Muhyi Al-Din Abdul Hamid, Dar Al-Fikr 


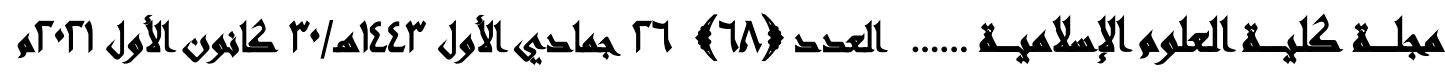

- Sunan Al-Bayhaqi Al-Kubra, Ahmed bin Al-Hussein Abu Bakr Al-Bayhaqi, Dar Al-Baz Library, Makkah Al-Mukarramah, 1414 - 1994, Muhammad Abdul Qadir Atta

- Sunan al-Bayhaqi al-Kubra, Ahmad ibn al-Husayn ibn Ali ibn Musa Abu Bakr al-Bayhaqi, t.: Muhammad Abd al-Qadir Atta, Dar al-Baz Library, Mecca, 1414 - 1994

- Sunan al-Tirmidhi, Muhammad bin Issa Abu Issa al-Tirmidhi, t.: Ahmad Muhammad Shakir and others, House of Revival of Arab Heritage, Beirut.

- Sunan Al-Darmi, Abdullah bin Abdul Rahman Abu Muhammad Al-Darmi, T: Fawaz Ahmed Zamerli, Khaled Al-Saba', Dar Al-Kitab Al-Arabi, Beirut, 1407, First

- Sahih al-Bukhari (The Complete Sahih al-Mukhtasar), Muhammad bin Ismail al-Bukhari, t.: d. Mustafa Dib Al-Bagha, Publisher: Dar Ibn Kathir, AlYamama - Beirut, third edition, 1407 - 1987,

- Sahih Muslim, Muslim bin Al-Hajjaj Abu Al-Hussein Al-Qushayri AlNisaburi, t.: Muhammad Fouad Abdel-Baqi, House of Revival of Arab Heritage, Beirut

- Gharib Hadith, Ibrahim bin Ishaq Al-Harbi, T: Suleiman Ibrahim Muhammad Al-Ayed, Publisher: Umm Al-Qura University, Edition: First, 1405

Fath al-Bari, Sharh Sahih al-Bukhari, Ibn Hajar al-Asqalani, T: Muhammad Fouad Abd al-Baqi, Dar al-Maarifa - Beirut, 1379

The Book of the Sunnah (and with it the Shades of Paradise in the Graduation of the Sunnah by: Muhammad Nasir al-Din al-Albani), Abu Bakr bin Abi Asim, The Islamic Office, i: First, 1400 


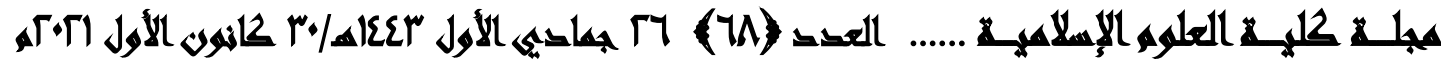

The Book of Sedition, Abu Abdullah Naim bin Hammad, T: Samir Amin AlZuhairi, Publisher: Al-Tawhid Library - Cairo, Edition: First, 1412

- Lisan Al-Mizan, Ibn Hajar Al-Asqalani, The Systematic Knowledge Circle India, Publisher: Al-Alamy Foundation for Publications, Beirut - Lebanon, Edition: Second, 1390

- Majmoo' al-Fatwas, Ibn Taymiyyah, compiled and arranged by Ibn Qasim, Edition of the Ministry of Islamic Affairs.

Musnad Ibn al-Jaad, Ali Ibn al-Jaad Ibn Obaid Abu al-Hasan al-Jawhari alBaghdadi, t: Amer Ahmad Haidar, Nader Foundation, Beirut, 1410 - 1990, first

- Musnad Abi Yala, Ahmed bin Ali bin Al-Muthanna Abu Yala Al-Mawsili AlTamimi, t.: Hussein Salim Asad, Dar Al-Mamoun Heritage, Damascus, 1404 1984, first

- The work of Ibn Abi Shaybah, Abu Bakr Abdullah Bin Muhammad Bin Abi Shaybah Al-Kufi, T: Kamal Youssef Al-Hout, Al-Rushd Library, Riyadh, 1409, First

- The work of Abd al-Razzaq al-San'ani, Abu Bakr Abd al-Razzaq ibn Hammam al-San'ani, t.: Habib al-Rahman al-Azami, The Islamic Office, Beirut, 1403, second

- Articles of the Islamists and the Differences of the Worshipers, Abul-Hasan Al-Ash'ari, Edited by: Helmut Ritter, Publisher: Franz Steizs, Edition: Third, 1400

- Minhaj al-Sunnah al-Nabawiyyah in refuting the words of the Qadariyya Shiites, Ibn Taymiyyah, T: Muhammad Rashad Salem, Imam University, i: First, 1406. 


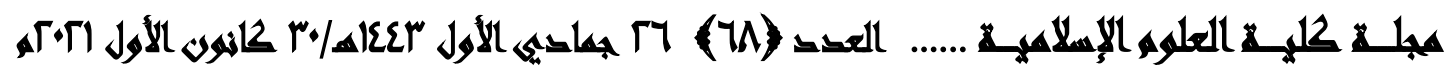

-Muwatta' of Imam Malik, Malik bin Anas Abu Abdullah Al-Asbahi, t.:

Muhammad Fouad Abdel-Baqi, House of Revival of Arab Heritage, Egypt 


\section{Abstract}

The value system in dialogue with the violator throughout history:

The Companions' dialogues with the Kharijites as a model:

an analytical study

Number

68

26

Jumada/ 1

$1443 \mathrm{AH}$

30th

December

$2021 \mathrm{M}$

The research goes to clarifying the system of values in dialogue with the violator through an inspection of our cultural heritage, and our inherent religious values. Al-Rashidah, and this position is represented in their various and varied dialogues with the Kharijites, whether that was at the beginning of their appearance - as is the case in the dialogue of Ali and Ibn Abbas, may God be pleased with them - or after the formation of their teams and the strength of their thorns, as in the dialogue of Ibn al-Zubayr and Jabir bin Abdullah, may God be pleased with them.

In these dialogues, I have come across important values in dialogue, which it is good to draw upon and work with, especially with the extremist currents of our time. The foresight of the Companions, their long patience, the strength of their argument, the uplifting of their morals, their justice with the opponent before approval, and their confidence in what they have of truth and guidance are evident. And the light. 